\title{
Oxytocin as an Anti-obesity Treatment
}

\author{
JingJing Niu ${ }^{1,2}$, Jenny Tong ${ }^{1,2}$ and James E. Blevins ${ }^{1,2 *}$ \\ ${ }^{1}$ VA Puget Sound Health Care System, Office of Research and Development, Medical Research Service, Department \\ of Veterans Affairs Puget Sound Health Care System, Seattle, WA, United States, ${ }^{2}$ Division of Metabolism, Endocrinology \\ and Nutrition, Department of Medicine, University of Washington School of Medicine, Seattle, WA, United States
}

OPEN ACCESS

Edited by: Lionel Carneiro,

The Ohio State University,

United States

Reviewed by:

Susan Erdman,

Massachusetts Institute

of Technology, United States

Liya Kerem,

Hadassah Medical Center, Israel

*Correspondence:

James E. Blevins

jeblevin@u.washington.edu

Specialty section:

This article was submitted to Neuroenergetics, Nutrition and Brain

Health,

a section of the journal

Frontiers in Neuroscience

Received: 18 July 2021

Accepted: 16 September 2021

Published: 13 October 2021

Citation:

Niu J, Tong J and Blevins JE (2021) Oxytocin as an Anti-obesity

Treatment.

Front. Neurosci. 15:743546. doi: 10.3389/fnins.2021.743546
Obesity is a growing health concern, as it increases risk for heart disease, hypertension, type 2 diabetes, cancer, COVID-19 related hospitalizations and mortality. However, current weight loss therapies are often associated with psychiatric or cardiovascular side effects or poor tolerability that limit their long-term use. The hypothalamic neuropeptide, oxytocin (OT), mediates a wide range of physiologic actions, which include reproductive behavior, formation of prosocial behaviors and control of body weight. We and others have shown that OT circumvents leptin resistance and elicits weight loss in diet-induced obese rodents and non-human primates by reducing both food intake and increasing energy expenditure (EE). Chronic intranasal OT also elicits promising effects on weight loss in obese humans. This review evaluates the potential use of OT as a therapeutic strategy to treat obesity in rodents, non-human primates, and humans, and identifies potential mechanisms that mediate this effect.

Keywords: obesity, food intake, energy expenditure, oxytocin - therapeutic use, adipose tissue

\section{SOURCE AND FUNCTIONS OF OXYTOCIN}

The obesity epidemic and its associated complications (Eckel et al., 2005; Cornier et al., 2008; Grundy, 2008) increase the risk for cardiovascular disease, cancer, type 2 diabetes (T2D), and death, including that from COVID-19 (Gao et al., 2020; Guo et al., 2020; Jordan et al., 2020; Michalakis and Ilias, 2020; Targher et al., 2020; Zhou et al., 2020) and has become a major health concern (Smyth and Heron, 2006). According to the National Center for Health Statistics, ageadjusted obesity prevalence between 1999-2000 and 2017-2018 has increased in adults from 30.5 to $42.4 \%$ (Hales et al., 2020). More than 78 million adults and 12.5 million children and adolescents in the United States are obese (Ogden et al., 2012) and the estimated annual medical cost of obesity is \$147 billion in 2008 United States dollars (Finkelstein et al., 2009). Some of the current pharmacologic therapies to treat obesity [i.e., Qsymia (phentermine + topiramate) and Contrave (naltrexone hydrochloride/bupropion hydrochloride)] can worsen sleep disturbance or worsen depression and are not well tolerated (Hollander et al., 2013; Kusminski et al., 2016; Halseth et al., 2018). While major advances in obesity pharmacotherapy have been made with semaglutide, a glucagon-like peptide-1 receptor agonist, which provides significant weight loss of 15\% (Wilding et al., 2021), it has been associated with gastrointestinal side effects, including nausea and diarrhea, in overweight and obese adults without diabetes (Rajagopal and Cheskin, 2021). Understanding the unique contributing factors to obesity and designing targeted interventions to lower the disease burden is an urgent need. 
While the neurohypophyseal hormone oxytocin (OT) is well recognized for its role in osmoregulation (Verbalis et al., 1995b), prosocial behavior (Striepens et al., 2011; Yamasue et al., 2012) and reproductive behaviors, including lactation (Braude and Mitchell, 1952) and uterine contraction (den Hertog et al., 2001), it is also being tested as a potential therapy to treat post-traumatic stress disorder (van Zuiden et al., 2017; Flanagan et al., 2018), schizophrenia (Striepens et al., 2011; Montag et al., 2012), autism spectrum disorder (Striepens et al., 2011; Yamasue et al., 2012; Miller, 2013; Young and Barrett, 2015), and obesity (Zhang et al., 2013; Lawson et al., 2015; Hsu et al., 2017). This excitement has translated to 535 completed, ongoing, or pending investigations in humans (ClinicalTrials.gov registry, National Institutes of Health). Given the current state of the obesity epidemic and lack of highly effective treatment options, this review focuses on OT as an anti-obesity therapy and mechanisms that contribute to these effects in genetically obese (Kublaoui et al., 2008; Tung et al., 2008; Maejima et al., 2011; Morton et al., 2012; Altirriba et al., 2014) and diet-induced obese (DIO) rodents (Deblon et al., 2011; Maejima et al., 2011, 2017; Zhang and Cai, 2011; Zhang et al., 2011; Morton et al., 2012; Edwards et al., 2021b) as well as in DIO non-human primates (Blevins et al., 2015) and obese humans (Zhang et al., 2013; Lawson et al., 2015; Thienel et al., 2016; Hsu et al., 2017) and assesses the translational and therapeutic potential of OT in humans. Due to the short duration of exposure of OT in the majority of clinical trials, one of the challenges that remains will be to examine the safety, tolerability, and efficacy of chronic intranasal OT use and to identify optimal dosing and frequency of administration to evoke clinically meaningful weight loss in individuals with obesity in the absence of adverse side effects (MacDonald et al., 2011; Tachibana et al., 2013; Zhang et al., 2013; Hsu et al., 2017; Cai et al., 2018). The barriers to the use of chronic treatment include concerns about OTelicited down-regulation of OT receptors (OTRs) (Insel et al., 1992; Peters et al., 2014; Freeman et al., 2018), the potential for increased anxiety (Peters et al., 2014; Winter et al., 2021), impairments in partner preference (Bales et al., 2013), aggression (Rault et al., 2013), hyponatremia (Bergum et al., 2009; Vallera et al., 2017), adverse cardiovascular effects (Pinder et al., 2002; Vallera et al., 2017; Snider et al., 2019) through interactions with vasopressin receptors (Snider et al., 2019), and feelings of distrust in humans with borderline personality disorder (Bartz et al., 2011) (see Miller, 2013; Leng and Ludwig, 2016a; Leng and Sabatier, 2017, for review).

The majority of central nervous system (CNS) OT is synthesized by magnocellular and parvocellular neurons in the paraventricular nucleus (PVN) as well as the magnocellular neurons in the supraoptic nucleus (SON) in mice (Young et al., 1996; Lein et al., 2007; Blouet et al., 2009; Maejima et al., 2009; Zhang et al., 2011; Sutton et al., 2014), rats (Swaab et al., 1975a,b; Sawchenko and Swanson, 1982; Sawchenko et al., 1984; Rinaman, 1998; Grinevich and Neumann, 2020), non-human primates (Antunes and Zimmerman, 1978; Sofroniew et al., 1981; Kawata and Sano, 1982; Ginsberg et al., 1994; Ragen and Bales, 2013), and humans (Dierickx and Vandesande, 1977; George, 1978; Paulin et al., 1978; Sukhov et al., 1993; Koutcherov et al., 2000) (see Gimpl and Fahrenholz, 2001; Ragen and Bales, 2013, for review). OT is also expressed in magnocellular neurons of the PVN and SON of the prairie vole but it still not clear if OT is expressed in parvocellular PVN neurons or whether OT projections to the nucleus accumbens (NAcc) originate from parvocellular or magnocellular neurons in prairie voles (Ross et al., 2009). In addition to the PVN and SON, OT is found in smaller amounts within magnocellular neurons in the anterior commissural nuclei (mouse) (Castel and Morris, 1988), anterior hypothalamus (mole-rat) (Rosen et al., 2008), accessory nuclei (mouse/rat) (Castel and Morris, 1988; Rinaman, 1998), preoptic area (mole-rat) (Rosen et al., 2008) and periventricular nuclei (mouse) (Castel and Morris, 1988). OT is also expressed in the bed nucleus of the stria terminalis (BNST; mole-rat/rat) (Rinaman, 1998; Rosen et al., 2008), caudal subzona incerta (hamsters) (Vaughan et al., 2011) dorsal hypothalamic area (hamsters) (Shi and Bartness, 2001), mediobasal preoptic area (mouse) (Castel and Morris, 1988), medial amygdala (molerat/rat) (Rinaman, 1998; Rosen et al., 2008) and septal region (rat) (Rinaman, 1998).

Mature OT and the carrier neurophysin are processed from the OT/neurophysin 1 prepropeptide (Brownstein et al., 1980) with both being stored in the axon terminals prior to release (Renaud and Bourque, 1991). It appears that the predominant role of neurophysin is to target, package and store OT within secretory granules prior to release (see Gimpl and Fahrenholz, 2001, for review). OT is released both locally from somatodendrites from magnocellular OT neurons in the SON and PVN (Pow and Morris, 1989; Zhang and Cai, 2011; Zhang et al., 2011; Wu et al., 2017) (see Ludwig and Leng, 2006, for review) and distally at axon terminals within the neurohypophysis that originate from magnocellular PVN and SON OT neurons. Recent findings indicate that magnocellular OT neurons also send collateral projections to a number of distal extrahypothalamic sites (Zhang et al., 2021). Magnocellular OT neurons within the PVN appear to send collaterals to the amygdala, caudate putamen and NAcc while those in the SON appear to send collaterals to the caudate putamen, NAcc, piriform cortex and lateral septum (Zhang et al., 2021). In addition, OT is also secreted from axon terminals from parvocellular PVN OT neurons that project to the hypothalamic arcuate nucleus (ARC) (Maejima et al., 2014) (mice), NAcc (Ross et al., 2009, prairie voles)/(Knobloch et al., 2012, rats), midbrain ventral tegmental area (VTA) (Shahrokh et al., 2010), hindbrain parabrachial nucleus (PBN) (Ryan et al., 2017) (mice), dorsal motor nucleus of the vagus (DMV) (Sawchenko and Swanson, 1982; Rinaman, 1998) nucleus tractus solitarius (NTS) (Sawchenko and Swanson, 1982; Rinaman, 1998; Sutton et al., 2014) (rats, mice), and spinal cord (Sawchenko and Swanson, 1982; Sutton et al., 2014) (rats, mice).

The extent to which OT is expressed in outgoing projections from the PVN to hindbrain CNS sites linked to the control of body weight appear to vary based on targets and species. Kirchgessner and Sclafani initially proposed that OT projections from the PVN to hindbrain were important in the control of food intake and body weight based on findings from their lab in which knife cuts that sever PVN-hindbrain projections were found to disrupt OT fibers (Kirchgessner et al., 1988) and result 
in hyperphagia and obesity (Kirchgessner and Sclafani, 1988). There is a large body of evidence linking hindbrain NTS OTRs in the control of homeostatic food intake (Kirchgessner and Sclafani, 1988; Kirchgessner et al., 1988; Blevins et al., 2003, 2004; Blouet et al., 2009; Baskin et al., 2010; Ho et al., 2014; Ong et al., 2015, 2017; Roberts et al., 2017; Edwards et al., 2021b). Studies have suggested that OT acts, in part, at NTS OTRs, to enhance the responsiveness of gastrointestinal satiation signals (Olson et al., 1991b; Blevins et al., 2003, 2015; Baskin et al., 2010; Ong et al., 2015, 2017) to limit meal size. More recent studies have implicated NTS OTRs in the control of food motivation and feeding reward (Wald et al., 2020). The role of hindbrain OTRs in the control of energy balance is further reviewed in Blevins and Ho (2013), Lawson et al. (2020), and McCormack et al. (2020) (food intake) and Section "What Receptor Populations Mediate Oxytocin's Effects on Brown Adipose Tissue (BAT) Thermogenesis and Energy Expenditure?". OT has been found to be expressed in up to (1) $6.3-10.1 \%$ of neurons with descending projections from the PVN to the dorsal vagal complex (DVC) (Olson et al., 1992) or (2) 11-16\% of neurons with descending projections the PVN to the medulla and spinal cord (Sawchenko and Swanson, 1982) (rats). A recent paper found that OT may be found in a substantially higher proportion of neurons that project to the DVC (28.9\%) in rats (Maejima et al., 2019). Current findings indicate that species differences (mice vs. rats) could account for the proportion or location where parvocellular PVN OT neurons project to the NTS. Namely, the majority of PVN OT neurons that project to the NTS appear to the reside within the caudal parvocellular PVN in rats (Rinaman, 1998). One recent study by Sutton et al. (2014) determined that there were few OT projections from the rostral parvocellular PVN that terminated within the NTS and that those that did exist were likely fibers of passage. In addition, those OT neurons that are expressed in the rostral PVN appear to project to spinal cord. These findings raise two questions: (1) Do parvocellular PVN OT neurons located within the caudal parvocellular PVN provide the bulk of OT innervation to the NTS in both mice and rats? (2) Is the parvocellular PVN OT projection to the NTS less dense in the mouse model compared to the rat model? Existing findings at least provide indirect evidence in support of a descending PVN to NTS OT projection in a mouse model (Blouet et al., 2009; Matarazzo et al., 2012; Ryan et al., 2017; Wu et al., 2017) and implicate an important role for OTRs within the caudal hindbrain in the control of body weight through reductions of food intake (homeostatic and hedonic) and increases in BAT thermogenesis or core temperature (as surrogate marker of energy expenditure) in both mice (Blouet et al., 2009; Matarazzo et al., 2012; Ryan et al., 2017; Edwards et al., 2021b) and rats (Baskin and Bastian, 2010; Blevins and Ho, 2013; Ho et al., 2014; Ong et al., 2015, 2017; Roberts et al., 2017; Edwards et al., 2021a).

PVN spinally projecting neurons (SPNs) that express OT appear to be involved with modulating cardiovascular function, stress response, thermoregulation and energy expenditure (via BAT thermogenesis) (see Hallbeck et al., 2001; Nunn et al., 2011, for review). Chemogenetic activation of PVN OT neurons, found to send dense projections to thoracic spinal cord in close proximity to choline acetyltransferase $(+)$ (ChAT; marker of cholinergic neurons) neurons, increased energy expenditure (oxygen consumption), tended to increase BAT temperature $(P=0.13)$ and increased Fos (marker of neuronal activation) within ChAT $(+)$ neurons of the thoracic spinal cord (Sutton et al., 2014) in Oxytocin-ires-Cre mice. The proportion of OT found in these PVN SPNs range between 20 and 25\% (Cechetto and Saper, 1988) and approximately 40\% (Hallbeck et al., 2001) (rats). The lateral parvocellular subdivision contained the highest proportion of PVN OT SPNs (47\%), followed by the dorsal parvocellular division (31\%) and the medial parvocellular division (24\%). It will be helpful to direct future studies to examine the extent to which OTRs within the spinal cord and hindbrain NTS are activated in response to cold and produce overlapping or distinct effects on BAT thermogenesis and energy expenditure.

Data from a combination of pharmacological, microdialysis and/or tract tracing studies suggest that PVN OT neuronal projections to the NAcc are involved with modulating social behavior and feeding reward (Ross et al., 2009; Herisson et al., 2016). Herisson et al. (2016) found that direct injections of OT into the NAcc core reduced intake of palatable sucrose and saccharin solutions, thus providing some of the first evidence linking OTRs within the NAcc core to feeding reward [see Klockars et al., 2015; Lawson et al., 2020 for role of NAcc OTRs in the control of food intake]. Based on the finding by Ross et al. (2009), OT fibers within the NAcc appear to be well conserved in terms of density and distribution in prairie voles, meadow voles, mice and rats. OT has also been found to be expressed in 23\% of PVN neurons that project to the NAcc in prairie voles (Ross et al., 2009). In the rat model, the number of fibers (and possibly terminals) found within the NAcc that originate from the PVN appear to vary based on region and if the analysis was done on the side ipsilateral or contralateral to the tracer injection site. Some reports indicate that the NAcc contains only a few OT fibers and/or terminals (Sofroniew, 1983) (not determined if origin was PVN or SON) but other reports that examined only those projections originating from the PVN found there to be up to 50 OT fibers (NAcc core; Knobloch et al., 2012) or $>50$ OT fibers (NAcc shell; Knobloch et al., 2012) with virtually no projections originating from the SON. These latter findings are consistent with a recent study in mice by Yao et al. (2017), who reported the presence of a low density ( $\sim 10-20$ fibers $)$ in the NAcc. The reason for the differences in OT fiber density within the NAcc across studies is not clear and may be due, in part, to differences in mouse strain, species and heterogeneity of neuronal projections within a CNS site. A recent study suggests that a subset of these projections may arise from either parvocellular PVN OT neurons or magnocellular PVN or SON neurons. Zhang et al. (2021) determined that a subset of magnocellular OT neurons within the PVN and SON send collateral projections to NAcc. It remains to be determined the extent to which such collateral projections to the NAcc may be important in the control of social behavior and feeding reward.

It is well established that the adiposity signal, leptin, acts, in part, in the ARC to reduce body weight in lean animals by activating anorexigenic [proopiomelanocortin (POMC)] neurons while simultaneously inhibiting orexigenic [neuropeptide Y 
(NPY)/agouti-related peptide (AGRP)] neurons (see Schwartz et al., 2000; Woods et al., 2000, for review). Several lines of evidence implicate ARC POMC neurons and the endogenous melanocortin 3/4 receptor (MC3R/MC4R) agonist, alphamelanocyte stimulating hormone ( $\alpha-\mathrm{MSH}$; derivative of POMC), as an important component relaying leptin input from the ARC to PVN OT neurons that are positioned to project to the hindbrain and enhance the hindbrain neuronal and satiety response to cholecystokinin (CCK), ultimately resulting in smaller meals (Seeley et al., 1997; Olszewski et al., 2001; Zhang and Felder, 2004; Blevins et al., 2009; Baskin et al., 2010). What remains unclear is the role of a recently identified OT projection from the PVN or SON to the ARC in the control of energy balance and whether this projection is primarily involved with the control of food intake (Maejima et al., 2014; Liao et al., 2020), energy expenditure, or both. Initially studies found that OT administration into the ARC reduced food intake (Maejima et al., 2014). Furthermore, chemogenetic stimulation of OTRexpressing neurons in the ARC reduced food intake and fastingelicited refeeding in mice (Fenselau et al., 2017) implicating an important role of endogenous OTR signaling within the ARC in the control of food intake. ARC POMC neurons appear to be downstream targets of OT action as POMC neurons express OTRs and OT stimulates cytosolic $\mathrm{Ca}(2+)$ from POMC neurons (Maejima et al., 2014). A complementary study by Fenselau reported that ARC OTR-expressing neurons are glutamatergic and that $50 \%$ of ARC OTR-expressing neurons expressed POMC (Fenselau et al., 2017). In addition, bath application of OT stimulated the firing rate of ARC OTR-expressing neurons in Oxtr-Cre:tdTomato mice (Fenselau et al., 2017). Through neuroanatomical tracing studies Maejima found that OT was expressed in $29 \%$ and $24 \%$ of PVN and SON neurons that project to the ARC, respectively (Maejima et al., 2014). In contrast, Liao et al. (2020) indicated that while there was dense OT fiber innervation of the ARC there appeared to be only "some axon terminals in the arcuate hypothalamus nucleus (Arc)" in OxtCre=C; Z/AP double-heterozygous mice. Yao et al. (2017) examined the density of OT fibers that originate from PVN OT neurons and found that OT fibers were found in medium density (>20 fibers) in the ARC in mice. Fenselau also identified that ARC-OTR expressing neurons also project to the PVN. Furthermore, optogenetic stimulation of terminals that arise from ARC-OTR (+) neurons that innervate the PVN result in the suppression of food intake (Fenselau et al., 2017). Future studies will need to determine the extent to which specific ARC-OTR cell populations may regulate both food intake and energy expenditure.

Existing data suggest that OTRs within the VMH are important in both the control of food intake and energy expenditure (see Sabatier et al., 2007; Sabatier et al., 2013; Lawson, 2017, for review). Noble and Klockars both demonstrated that direct injections of OT into the VMH reduced chow intake but had no effect on more palatable saccharin or sucrose solutions (Klockars O. A. et al., 2017) in rats (Noble et al., 2014; Klockars O. A. et al., 2017). These findings link VMH OTRs more so to the control of homeostatic feeding rather than feeding reward. While OT has been recently described in projections from the
PVN to the VMH (Nasanbuyan et al., 2018) in mice existing data suggest that OT fibers within the VMH are likely fibers of passage. These findings are also consistent with a recent report by Yao et al. (2017), who reported the presence of low density of OT fibers ( $\sim 10-20$ fibers) within the VMH originated from the PVN in mice. While OT fibers were detected within regions of the ventrolateral VMH (Liao et al., 2020) that express OTRs in mice (Nasanbuyan et al., 2018). Liao further determined that there were "almost no axon terminals" within the VMH (Liao et al., 2020). Leng et al. (2008) further commented that there was "virtually complete absence of OT-containing fibres in the $\mathrm{VMH}$ " and that "The VMH contains very few fibres that show any immunoreactivity for either OT or vasopressin" and that "it is not known whether the few OT fibres there are 'stray' axons or dendrites of magnocellular neurons or come from parvocellular neurons of the PVN." In addition, Leng commented that "So far, there has been no direct evidence of any projection to or synaptic innervation of VMH neurons by OT neurons from the parvocellular region of the PVN" (Leng et al., 2008). Thus, while there does not appear to be data to support a PVN OT projection to the $\mathrm{VMH}$ in mice or rats, direct administration of OT into the $\mathrm{VMH}$ reduces food intake (Noble et al., 2014; Klockars O. A. et al., 2017) and increases energy expenditure (Noble et al., 2014). Leng and colleagues have postulated that OT, following somatodendritic release from magnocellular OT neurons (within the SON or PVN), could be an important source of endogenous OT that could reach VMH OTRs by diffusion (1) to the ventricles and subsequent transport through cerebrospinal fluid (CSF) or (2) within the brain (Ludwig and Leng, 2006; Sabatier et al., 2007) (see Leng and Ludwig, 2008; Leng et al., 2008; Sabatier et al., 2013; Leng and Sabatier, 2017, for review). The hypothesis that somatodendritic release of OT acts, in part, at VMH OTRs to suppress food intake is particularly attractive as Leng and Sabatier (2017) indicated that dendritic release is "delayed and long-lasting, potentially contributing to post-prandial satiety." In addition, (1) large amounts of OT are released somatodentrically from magnocellular OT neurons, (2) the SON and PVN are found in close proximity to the $\mathrm{VMH}$, (3) there is robust expression of OTRs within the VMH, and (4) magnocellular OT neurons within the SON and neurons within the $\mathrm{VMH}$ are activated in response to food intake (Johnstone et al., 2006). Collectively, these studies have begun to address the potential source of endogenous OT to VMH OTRs and whether this source of endogenous OT to the VMH may also be important in the control of food intake (Leng et al., 2008; see Leng and Ludwig, 2008; Sabatier et al., 2013; Leng and Sabatier, 2017, for review).

The OT projection from the PVN to the VTA has been implicated in the control of social behavior and feeding reward (Mullis et al., 2013; Liu et al., 2020b; Wald et al., 2020) (also see Klockars et al., 2015; Lawson et al., 2020, for additional information on VTA OTRs in the control of food intake). Previous data from Mullis et al. (2013) indicate that direct administration of OT into the VTA reduces consumption of highly palatable $10 \%$ sucrose solution. Consistent with these findings, Wald et al. (2020) recently found that OT administration into the VTA reduced bar presses in order to consume palatable sucrose pellets, a finding that suggests OT 
decreases the willingness to work to obtain sucrose pellets. In addition, they found that VTA administration of OT also reduced food seeking behavior toward palatable chocolate pellets (Wald et al., 2020). Liu et al. (2020b) subsequently provided mechanistic data using in vivo fiber photometry to suggest that OT reduces food cue (sucrose)-elicited activation of dopamine neurons within the VTA suggesting that OT may reduce reward intake, in part, through an inhibitory effect on dopamine neurons and their response to rewarding food cues. Eric Krause and colleagues provided neuroanatomical confirmation that a subpopulation of VTA OTR $(+)$ neurons express dopamine (10\%) [in addition to glutamate $(\approx 44 \%)$ ], some of which project to the NAcc (Peris et al., 2016). Recent reports indicate there is a direct projection from the PVN to the VTA in rats (Shahrokh et al., 2010) and Liao indicated there were "some branch-like terminals" within the VTA in OxtCre = C; Z/AP double-heterozygous mice (Liao et al., 2020). Yao et al. (2017) examined the density of OT fibers that originate from PVN OT neurons and found that OT fibers were found in medium density ( $>20$ fibers) in VTA. A separate study found that approximately $20 \%$ of PVN OT neurons were found to project to the VTA following green retrobead injections into mice expressing tdTomato under control of the Oxt promoter (Xiao et al., 2017). Beier extended these findings and found that approximately 6 and 13\% of PVN OT neurons synapsed onto VTA dopamine and GABA neurons in DAT-Cre and GAD2Cre mice, respectively (Beier et al., 2015). These findings are consistent with those from Peris et al. (2016) who demonstrated that approximately $5 \%$ of OTR $(+)$ neurons within the VTA co-localized with tyrosine hydroxylase in OTR-Cre mice.

Data from pharmacological and chemogenetic studies implicate a role for the PVN OT projection to the PBN in the control of fluid intake (Ryan et al., 2017). Ryan et al. (2017) demonstrated that PBN OTR (+) neurons were activated by $\mathrm{NaCl}$ or water repletion. In addition, chemogenetic activation of PBN OTRs resulted in a suppression of fluid intake (Ryan et al., 2017). Photostimulation of OT terminals within the PBN also resulted in activation of $22 \%$ of PBN OTR ( + ) neurons (Ryan et al., 2017). Ryan further demonstrated that PBN receives direct innervation from PVN OT neurons (Ryan et al., 2017). It is notable that Sutton et al. (2014) demonstrated very little OT fiber innervation within the PBN that originated from the rostral PVN although it might be possible that OT neurons in more caudal regions of the PVN may innervate the PBN more heavily. Collectively, the findings by Ryan demonstrate that OTR-expressing neurons within the PBN are important in the control of fluid homeostasis.

Similar to the VMH, the raphe pallidus is an area that receives virtually little to no innervation from PVN OT neurons despite receiving dense projections from other neuron subtypes within the PVN (Luo et al., 2019). Sutton et al. (2014) reported the existence of few OT terminals within the raphe pallidus. Despite this, Kasahara et al. (2015) have determined that OTR (+) neurons are activated in response to cold and that increased OTR signaling within the rostral raphe pallidus helps restore deficits in response to cold-induced thermogenesis in OT receptor deficient mice (see sections "Does Endogenous Oxytocin Impact ColdInduced Thermogenesis and Energy Expenditure?" and "What
Receptor Populations Mediate Oxytocin's Effects on Brown Adipose Tissue Thermogenesis and Energy Expenditure?" for additional information).

Data from pharmacological and chemogenetic studies implicate a role for the PVN OT projection to the CeA in the control of fear responses (Knobloch et al., 2012) and food intake (Klockars et al., 2018) (also see Lawson et al., 2020, for additional information on CeA OTRs in the control of food intake). Klockars demonstrated that direct injections of OT into the CeA reduced chow intake but had no effect on more palatable saccharin or sucrose solutions in rats (Klockars et al., 2018) while OT within the basolateral amygdala appeared to reduce intake of both chow and palatable solutions. These findings suggest that OTRs within the CeA may be more involved in the control of homeostatic feeding while those in the basolateral amygdala may participate in both homeostatic and feeding reward. Within the CeA, Yao et al. (2017) examined the density of OT fibers that originate from PVN OT neurons and found a small number of fibers within the CeA ( $\sim 0-10$ fibers) (mice). In contrast, Liao et al. (2020) identified that there are "many axon terminal branches cover the whole central amygdala region including the central amygdala medial division (CeM), central amygdala lateral division $(\mathrm{CeL})$ and central amygdala capsular part $(\mathrm{CeC})$ " using a $\mathrm{Oxt}^{\mathrm{Cre}} /{ }^{+}$; Z/AP mice. OT fibers from the PVN are also found to innervate the CeA $(\sim 12-36$ fibers/side) and medial amygdala (MeA) ( 30-59 fibers/side) in rats (Knobloch et al., 2012). The reasons for the differences in OT fiber density within the CeA between studies are unclear although differences with respect to mouse strain, species, and heterogeneity of neuronal projections within a CNS site may play a role.

Oxytocin is also expressed in peripheral tissues including the heart (rats; Jankowski et al., 1998) and rat and human gastrointestinal (GI) tract (Ohlsson et al., 2006; Welch et al., 2009; Paiva et al., 2021) (including neurons of myenteric and submucosal plexus of enteric nervous system) (Paiva et al., 2021) as well as the islets of Langerhans of the pancreas and Leydig cells of the testes in rats (Paiva et al., 2021), although the stimuli that impact the release of OT within these areas, where it is released and extent to which these peripheral sources of OT contribute to energy balance is not clear.

\section{OXYTOCIN RECEPTOR EXPRESSION IN CENTRAL NERVOUS SYSTEM SITES ASSOCIATED WITH ENERGY BALANCE IN RODENTS, NON-HUMAN PRIMATES AND HUMANS}

There is widespread expression of OTRs in CNS sites that are linked to the control of food intake or BAT thermogenesis based on being anatomically positioned to control sympathetic outflow to interscapular BAT (IBAT) to potentially control energy expenditure. There is wide overlap in OTR distribution in mice and rats in areas that include the forebrain hypothalamus [ARC, MPA, suprachiasmatic nucleus, and VMH]/mouse (Gould and Zingg, 2003; Yoshida et al., 2009; Hidema et al., 2016; 
Fenselau et al., 2017; Ryan et al., 2017)/rat (van Leeuwen et al., 1985; Vaccari et al., 1998; Klockars O. A. et al., 2017)] and basal ganglia [e.g., NAcc and CeA/mouse (Yoshida et al., 2009; Hidema et al., 2016; Ryan et al., 2017)/rat (van Leeuwen et al., 1985; Tribollet et al., 1992; Vaccari et al., 1998)], midbrain VTA [mouse (Peris et al., 2017)/rat (Vaccari et al., 1998)] as well as hindbrain PBN [mouse (Ryan et al., 2017)], rostral medullary raphe (raphe pallidus) [mouse (Yoshida et al., 2009; Kasahara et al., 2015; Sun et al., 2019)], AP [mice (Gould and Zingg, 2003; Yoshida et al., 2009; Ryan et al., 2017)], DMV [mouse (Ryan et al., 2017)/rat (Tribollet et al., 1992; Verbalis et al., 1995a; Vaccari et al., 1998)], NTS [mouse (Gould and Zingg, 2003; Yoshida et al., 2009; Sun et al., 2019)/rat (Verbalis et al., 1995b; Baskin and Bastian, 2010; Ong et al., 2015, 2017)] and spinal cord [mouse (Wrobel et al., 2011)/rat (Reiter et al., 1994)]]. OTRs are also found in the SON and PVN in rats (Yoshimura et al., 1993) and subsequent studies identified OTRs on the somata and dendrites of magnocellular OT neurons in lactating female rats but not in male rats (FreundMercier et al., 1994) although it is not yet certain if detectability in the female rats is due, in part, to pre-treatment with the OTR antagonist (Freund-Mercier et al., 1994). These autoreceptors are not found in male rats or in untreated lactating rats and have been proposed to contribute to the feed forward effect of OT on its own release during the milk letdown reflex (Freund-Mercier et al., 1994; Freund-Mercier and Stoeckel, 1995). In contrast to rodents, OTRs appear to have a more restricted distribution in CNS sites linked to energy balance within a variety of non-human primate species (cynomolgus, rhesus macaque, and common marmoset) [NAcc, preoptic area, VMH, DMV, and spinal cord (Boccia et al., 2001; Schorscher-Petcu et al., 2009; Freeman et al., 2014)] and humans (CeA, anterior hypothalamus, MPA, PVN, VMH, AP, NTS and spinal cord) (Loup et al., 1989, 1991; Boccia et al., 2013). OT fibers appear to be in proximity of OTR $(+)$ neurons within the ventrolateral VMH in the mouse (Nasanbuyan et al., 2018) (suggesting the presence of synaptic terminals). Similarly, in the rat, the ventrolateral VMH also expresses OT fibers (Daniels and Flanagan-Cato, 2000; Flanagan-Cato et al., 2001) although there appear to be very few OT fibers elsewhere within the VMH of the rat (Caldwell et al., 1988; Jirikowski et al., 1988; Schumacher et al., 1989, see Leng et al., 2008, for review). As mentioned earlier, others have proposed that OT may reach OTRs by diffusion (see Verbalis et al., 1995a; Verbalis, 1999, for review) from magnocellular OT neurons within the SON (see Leng et al., 2008; Sabatier et al., 2013, for review), through the third ventricle (3V) following dendritic release of OT from the PVN or possibly by axonal release within the $\mathrm{VMH}$ (Leng et al., 2008). It is important to note that many of the more recent studies have utilized more advanced and complementary screening tools to assess OTR expression in mice compared to the earlier pharmacological and/or antibody screening tools used to identify OTRs in rats in the 1980s and 1990s. Questions about selectivity and specificity of the antibodies and pharmacological tools used in earlier studies limit our ability to more firmly identify species differences, nonetheless, overlapping patterns of OTR distribution within the basal ganglia, hypothalamus, midbrain, hindbrain and spinal cord implicate potentially important roles of these areas in contributing to the control of food intake (homeostatic and hedonic feeding) and energy expenditure that appear to be well conserved across species. OTRs are also found in peripheral sites that include the GI tract (Qin et al., 2009), nodose ganglion (Welch et al., 2009; Brierley et al., 2021), skeletal muscle (Elabd et al., 2014; Gajdosechova et al., 2014, 2015) and bone (Copland et al., 1999; Colucci et al., 2002; Tamma et al., 2009; Colaianni et al., 2012) in rodents as well as white adipocytes or white adipose tissue in both rodents and humans (Muchmore et al., 1981; Schaffler et al., 2005; Tsuda et al., 2006; Altirriba et al., 2014; Gajdosechova et al., 2014, 2015; Yi et al., 2015; Sun et al., 2019). Recent findings by both Sun et al. (2019) and Yuan et al. (2020) have also reported that OTRs are expressed on brown adipocytes or brown adipose tissue. The potential role OTRs on white and brown adipocytes, the GI tract, vagal sensory afferent nerves, skeletal muscle and bone in contributing to the effects of circulating OT in the control of energy balance, muscle maintenance and bone mass is discussed in Section "How Does Oxytocin Impact Body Composition".

\section{IS OXYTOCIN EFFECTIVE AT REDUCING BODY WEIGHT IN RODENT MODELS OF OBESITY?}

Previous studies have shown that central, systemic [intraperitoneal (IP), subcutaneous (sc) or intravenous], intraoral (in combination with a proton pump inhibitor) (Maejima et al., 2020) or intranasal administration of OT reduces energy intake, body weight or weight gain in DIO mice and rats (Deblon et al., 2011; Maejima et al., 2011, 2017; Zhang and Cai, 2011; Zhang et al., 2011; Morton et al., 2012; Roberts et al., 2017; Labyb et al., 2018; Seelke et al., 2018; Snider et al., 2019; Edwards et al., 2021b), genetically obese mice and rats [e.g., obese Zucker fatty $(f a / f a)$ rat, Koletsky (fak/fak) rat, ob/ob, db/db and Sim $1^{ \pm}$ mice] (Kublaoui et al., 2008; Maejima et al., 2009; Morton et al., 2012; Altirriba et al., 2014; Iwasaki et al., 2015; Plante et al., 2015; Balazova et al., 2016), ovariectomized rats (Iwasa et al., 2019b), a rat model of dihydrotestosterone-induced polycystic ovary syndrome (PCOS) (Iwasa et al., 2019a), as well as in DIO rhesus monkeys (Blevins et al., 2015).

Numerous findings suggest that OT reduces body weight or weight gain in rodents and non-human primates, in part, by reducing energy intake (see Blevins and Baskin, 2015; Lawson et al., 2020; McCormack et al., 2020, for review). It is well documented that OT reduces food intake (including chow, purified low and high fat diet or sucrose solution) following systemic (Arletti et al., 1989, 1990; Deblon et al., 2011; Maejima et al., 2011, 2015, 2017; Morton et al., 2012; Altirriba et al., 2014; Ho et al., 2014; Blevins et al., 2015; Iwasaki et al., 2015, 2019; Balazova et al., 2016; Klockars A. et al., 2017; Iwasa et al., 2019b, 2020; Erdenebayar et al., 2020), intranasal (Maejima et al., 2015) or CNS administration (Arletti et al., 1989, 1990; Olson et al., 1991a; Lokrantz et al., 1997; Rinaman and Rothe, 2002; Kublaoui et al., 2008; Deblon et al., 2011; Morton et al., 2012; Mullis et al., 2013; Ho et al., 2014; Noble et al., 2014; Ong et al., 2015; Herisson et al., 2016; Klockars O. A. et al., 2017; Klockars et al., 2018; Liu et al., 2020a; Edwards et al., 2021a,b). While many 
such investigations have targeted the lateral ventricles, $3 \mathrm{~V}$ and $4 \mathrm{~V}$, which lack the anatomical resolution to differentiate receptor populations, recent findings indicate that OT reduces food intake following direct injections into the ARC (Maejima et al., 2014), CeA (Klockars et al., 2018), basolateral amygdala (Klockars et al., 2018), VMH (Noble et al., 2014; Klockars O. A. et al., 2017), striatum (NAcc core) (Herisson et al., 2016), midbrain VTA (Mullis et al., 2013) and hindbrain NTS (Ong et al., 2015), many of which express OTRs (see section "Oxytocin Receptor Expression in Central Nervous System Sites Associated With Energy Balance in Rodents, Non-human Primates and Humans") and are also innervated by OT neurons within the PVN or SON (see Figure 1 and see section "Source and Functions of Oxytocin"). Importantly, OT, at doses that reduce food intake when given into the CNS or periphery, is not associated with increased kaolin diet intake (referred to as pica behavior/readout of visceral illness) (Zhang et al., 2011; Blevins et al., 2016; Roberts et al., 2017; Edwards et al., 2021b) or a conditioned taste aversion test (Zhang et al., 2011; Noble et al., 2014; Iwasaki et al., 2015; Blevins et al., 2016) in lean and obese mice (Zhang et al., 2011; Iwasaki et al., 2014; Roberts et al., 2017; Edwards et al., 2021b) and rats (Noble et al., 2014; Blevins et al., 2016; Roberts et al., 2017). Together, these findings suggest that OT, either given alone, or in

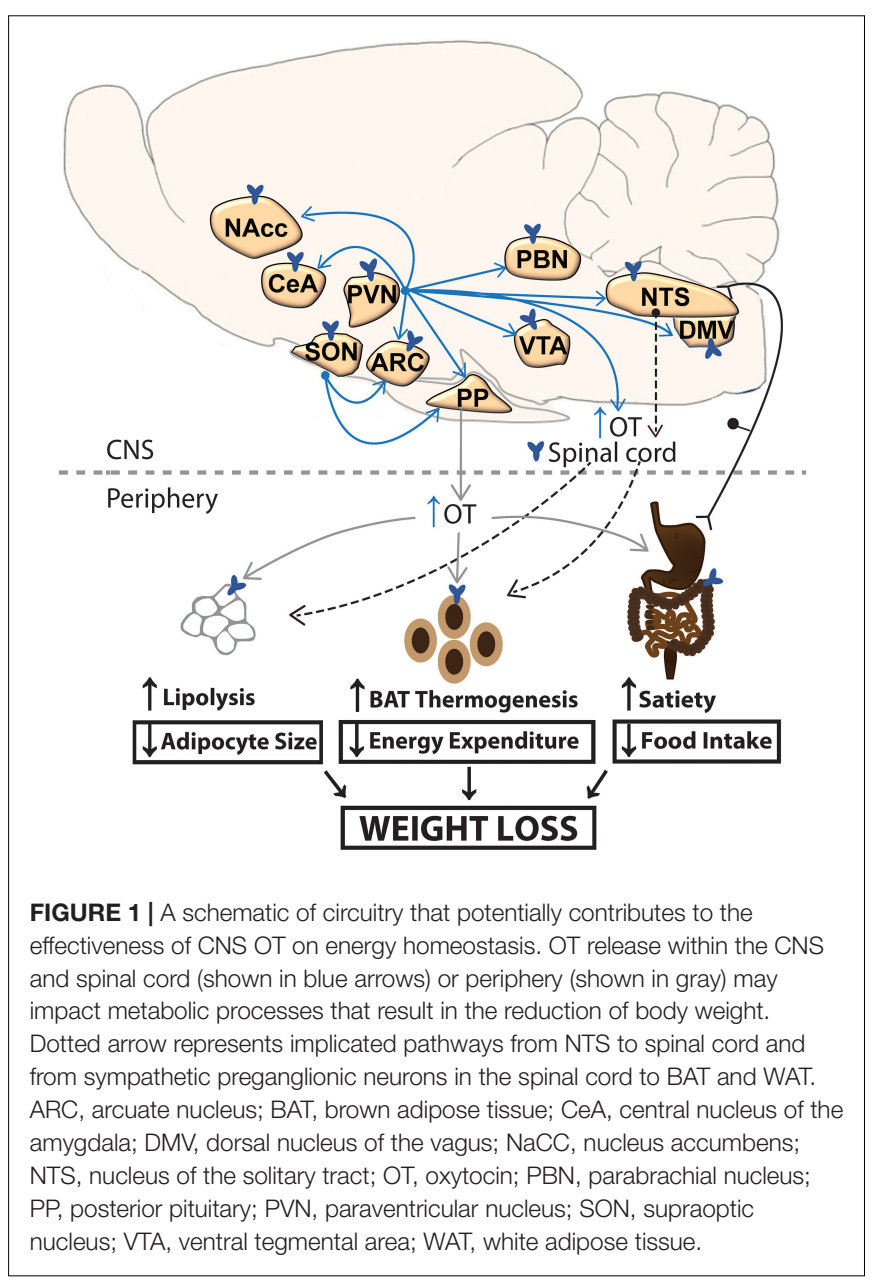

combination with other drugs, could be an attractive anti-obesity therapy in DIO and genetically obese rodents and DIO nonhuman primates. In Section "Does Exogenous Oxytocin Increase Energy Expenditure?," we will review the potential role of energy expenditure in contributing to the effects of OT on weight loss in rodents and non-human primates.

\section{DOES EXOGENOUS OXYTOCIN INCREASE ENERGY EXPENDITURE?}

Numerous studies provide both direct and indirect evidence to indicate that OT is important in the control of energy expenditure. Indirect evidence stemming from pair-feeding studies (amount of food given to vehicle-treated animals is equal to that of OT-treated animals) indicate that OT-treated animals lose more weight relative to pair-fed control animals (Deblon et al., 2011; Altirriba et al., 2014; Blevins et al., 2016). These findings were evident following chronic lateral ventricular infusions of OT (16 nmol/day) in high fat diet-fed male rats (weeks 5 to 7 of high fat diet feeding) or chronic sc infusions of OT ( $50 \mathrm{nmol} /$ day) into male high fat diet-fed rats (weeks 5 to 7 of high fat diet, $45 \%$ kcal from fat) (Deblon et al., 2011), male lean standard diet-fed rats (Deblon et al., 2011) as well as in male ob/ob mice (Altirriba et al., 2014). Note that it is not clear the extent to which the rats used in the study by Deblon et al. (2011) were DIO without having the body weight and body composition data pre- and post-dietary intervention and they were only maintained on the high fat diet for a relatively short period of time ( 5 to 7 weeks). However, similar findings have been obtained following a single acute injection of OT (Morton et al., 2012 ) in male low-fat diet-fed ( $10 \%$ kcal from fat) or high fat dietfed (45\% kcal from fat) Sprague Dawley rats after having been maintained on the respective diets for $\sim 4$ months. These findings suggest that, in addition to reductions of food intake, other mechanisms (including energy expenditure) also contribute to OT-elicited weight loss. In addition, OT infusions over a 14day period were found to reduce body weight gain despite no changes in cumulative 14-day food intake (Deblon et al., 2011). Furthermore, the findings from long-term administration studies suggest that OT appears to become less effective at reducing food intake despite an unimpaired and persistent reduction of body weight gain or body weight over this period of time (Deblon et al., 2011; Maejima et al., 2011, 2017; Altirriba et al., 2014; Blevins et al., 2016; Roberts et al., 2017).

The most direct evidence in support of an important role for OT in the control of energy expenditure stems from pharmacological studies that included measurements of energy expenditure. Acute administration of OT into the $3 \mathrm{~V}$ or $\mathrm{VMH}$ boosted energy expenditure or oxygen consumption as determined by indirect calorimetry in rodents (Zhang and Cai, 2011; Zhang et al., 2011; Noble et al., 2014). These effects were recapitulated following peripheral administration in a translational DIO non-human primate (rhesus monkey) model (Blevins et al., 2015). In addition, other paradigms in which OT was administered in a paradigm that elicited weight loss, OT was not found to elevate energy expenditure (Blevins et al., 2016). 
One explanation for these findings might be that chronic administration of OT could be important in attenuating the counter-regulatory mechanisms that result in weight regain in the setting of prolonged weight loss. Thus, OT, in the setting of weight loss, might prevent the drop in energy expenditure that accompanies prolonged weight loss and restore levels of energy expenditure to that of control animals (Blevins et al., 2016) and mice (Maejima et al., 2011). It is important to acknowledge that energy expenditure was not measured throughout the extent of the treatment period across the chronic treatment studies. We have previously shown that chronic $3 \mathrm{~V}$ infusions of OT stimulate IBAT temperature during a time that coincides with OT-elicited weight loss (days 2-3 of infusion period) (Roberts et al., 2017) and that $3 \mathrm{~V}$ OT appeared to maintain IBAT temperature to that of control animals for the remainder of the infusion period (unpublished findings). In addition, following minipump removal and throughout the 4-week washout period, IBAT temperature appeared to be slightly lower in rats that had been previously treated with chronic $3 \mathrm{~V}$ OT relative to vehicle treated control rats (unpublished findings). It is possible that timing of energy expenditure in relation to OT-elicited weight loss is important and that chronic administration of OT may stimulate BAT thermogenesis and energy expenditure at the onset of OT-elicited weight loss and function, in part, to help maintain weight loss by preventing a drop in BAT thermogenesis and energy expenditure (Blevins et al., 2016) that accompanies prolonged reductions of food intake and weight loss in animals (Fosgerau et al., 2014) and humans (Rosenbaum et al., 2002, 2005, 2010; Schwartz and Doucet, 2010). Current studies are underway to determine the extent to which SNS innervation of BAT is required for OT to increase energy expenditure and elicit weight loss.

\section{Does Exogenous Oxytocin Increase Brown Adipose Tissue Thermogenesis and Browning of White Adipose Tissue?}

We know from recent studies that acute forebrain (3V) and hindbrain $(4 \mathrm{~V})$ injections of OT stimulate IBAT temperature [functional measure of BAT thermogenesis (Song et al., 2008; Leitner and Bartness, 2009; Vaughan et al., 2011)] in both chowfed and DIO rats and mice (Roberts et al., 2017; Edwards et al., 2021b). In addition, chronic infusions of OT into the $3 \mathrm{~V}$ stimulates IBAT temperature at the start of OT-elicited reductions of body weight in DIO rats (Roberts et al., 2017) raising the possibility that $\mathrm{BAT}$ thermogenesis might contribute to weight loss in response to OT treatment. OT injections into the midbrain (median raphe) or $4 \mathrm{~V}$ also stimulated core temperature in mice (Yoshida et al., 2009) and rats (Ong et al., 2017). These findings shed light on the potential contribution of OT in stimulating BAT temperature to help maintain body temperature (Cannon and Nedergaard, 2004) particularly during cold stress (Kasahara et al., 2007, 2013, 2015; Xi et al., 2017). In addition to maintaining core temperature during cold challenges, changes in IBAT temperature are often found to precede and contribute to changes in core temperature under conditions of fever and stress (Kataoka et al., 2014).
The majority of studies indicate that the effects of OT on IBAT temperature appear to contribute to non-shivering thermogenesis (mediated by BAT thermogenesis) rather than shivering thermogenesis (generated by movement of skeletal muscle). Namely, chronic administration of OT is not associated with elevations in locomotor activity in rats (Deblon et al., 2011; Blevins et al., 2016; Iwasa et al., 2019b) or mice (Maejima et al., 2011). Data from Carson et al. (2010) indicate that peripheral administration of OT attenuated methamphetamineelicited increases in locomotor activity in rats. In addition, peripheral administration of OT decreased locomotor activity in rats; central administration of an OTR antagonist also blocked this effect (Angioni et al., 2016). Furthermore, central administration of OT blocked the ability of central delivery of an OT receptor antagonist to stimulate locomotor activity. However, two findings raise the possibility that increased locomotor activity may contribute, in part, to the elevated IBAT temperature. Sutton et al. (2014) found that DREADD-elicited stimulation of PVN OT neurons in Oxytocin-ires-Cre mice was associated with a small elevation of locomotor activity, energy expenditure and sc IBAT temperature and a close to significant elevation of sc IBAT temperature $(P=0.13)$. Another study found that VMH administration of OT stimulated short-term physical activity in rats for 1-h post-injection but these effects failed to coincide with the more prolonged effects of $3 \mathrm{~V}$ or $4 \mathrm{~V}$ OT on IBAT temperature that we have found in our studies in rats (Roberts et al., 2017) and mice (Roberts et al., 2017; Edwards et al., 2021b). Yuan et al. (2020) recently reported that OT may stimulate markers of thermogenesis in skeletal muscle [including uncoupling protein3 (UCP-3)] and further work will need to be determined as to what role this mechanism plays in contributing to the effects of OT on energy balance given that OT has been found to have (1) no impact on locomotor activity, (2) reduce locomotor activity, or (3) produce only short-term changes in physical activity that do not coincide with the temporal profile of $\mathrm{OT}$ on IBAT temperature.

Previous studies indicate that OT may help stimulate the transformation of white adipocytes to more metabolically active "brown" adipocytes. The process of "browning" (Nedergaard and Cannon, 2014) of WAT may involve the transdifferentiation or de novo synthesis of brown adipocytes in white adipose tissue (WAT) culminating with increased expression of uncoupling protein-1 (UCP-1) and the production of heat (Cannon and Nedergaard, 2004). We recently demonstrated that hindbrain $(4 \mathrm{~V})$ infusions of OT ( $16 \mathrm{nmol} /$ day) elicit browning of inguinal white adipose tissue (IWAT) (as indicated by increased UCP1 expression) in the IWAT of chow-fed mice (Edwards et al., 2021b) but not in DIO mice. In addition, chronic sc OT infusions (125 ng/kg/h or $\approx 66.2 \mathrm{nmol} /$ day) also appeared to stimulate UCP-1 expression in sc fat of $d b / d b$ mice (Plante et al., 2015) but the UCP-1 staining was not quantified. A more recent study by Yuan et al. (2020) reported that chronic sc OT infusions (100 nmol/day) increased UCP-1 expression in IWAT but not in epididymal WAT (EWAT) of high fat diet-fed mice. It is not clear why Yuan found elevated expression of UCP-1 in IWAT of high fat diet-fed mice while we did not find a significant effect of $4 \mathrm{~V} \mathrm{OT}$ to increase UCP-1 in IWAT from DIO mice in our 
study. It is important to note that the dose used in Yuan's study in DIO mice was approximately 6.25-fold higher than that found to be effective following $4 \mathrm{~V}$ infusions in our study and that higher doses may be required to elicit "browning" of IWAT in DIO mice relative to chow-fed mice. It is difficult to compare across studies as chow-fed mice were also not examined in Yuan's study. Given the existence of outgoing polysynaptic projections from the PVN OT neurons to IWAT (Shi and Bartness, 2001) and EWAT (Shi and Bartness, 2001; Stanley et al., 2010), it is possible that OT acts locally at hindbrain or spinal cord OTRs to elicit browning. In addition, OT may also act peripherally to induce browning of WAT through a direct action on OTRs found on adipocytes (Muchmore et al., 1981; Schaffler et al., 2005; Tsuda et al., 2006; Deblon et al., 2011; Yi et al., 2015) in either IWAT (Gajdosechova et al., 2015) or EWAT depots (Muchmore et al., 1981; Altirriba et al., 2014; Gajdosechova et al., 2014, 2015). Sun et al. (2019) recently found that OT may suppress browning, when it is applied directly to adipocytes in vitro as indicated by reduced expression of brown adipocyte specific markers (Cox7a, Cox8b, Cebpb, Retn, and Cidea). Further in vitro studies should also include UCP-1 which was not examined in this study. It will be important to determine if the conflicting data are due, in part, to dose, route of administration, acute vs. chronic application, in vitro vs. in vivo conditions, lack of overlap of brown adipocyte specific markers between studies and if these effects can be blocked by an OTR antagonist. These findings raise the possibility that OT may stimulate energy expenditure through multiple CNS and/or peripheral sites and raise the question as to the extent to which BAT thermogenesis and "browning" of WAT contribute to these effects.

\section{Does Endogenous Oxytocin Impact Cold-Induced Thermogenesis and Energy Expenditure?}

Oxytocin receptor or OT deficient mice are associated with adultonset obesity (Kasahara et al., 2007; Takayanagi et al., 2008; Camerino, 2009; Sun et al., 2019) that appears at 8 (Tamma et al., 2009), 10 (Kasahara et al., 2007) or 16 weeks (Camerino, 2009) in OT null mice and 12 weeks in OTR null mice (Takayanagi et al., 2008). The adult-onset obesity in the OT and OTR null mice is characterized by increased body weight (Kasahara et al., 2007; Takayanagi et al., 2008; Camerino, 2009), fat mass (Sun et al., 2019) and/or fat pad weight (Takayanagi et al., 2008; Camerino, 2009). The finding that this occurs despite having no changes in overall daily food intake (Kasahara et al., 2007; Takayanagi et al., 2008; Camerino, 2009) suggests that other mechanisms (such as impairments in energy expenditure) may contribute to their obesity phenotype. Daily food intake in OT or OT receptor deficient mice is normal regardless of whether the mice were fed chow (Amico et al., 2005; Takayanagi et al., 2008; Camerino, 2009), sucrose-enriched chow (Amico et al., 2005) or high fat diet (Takayanagi et al., 2008). These findings were confirmed in both chow-fed and high fat diet-fed mice with diphtheria toxin-elicited reductions of PVN and SON OT neurons (Wu et al., 2012; Xi et al., 2017). While one other study also reported that OTR deficient mice do not have any overall changes in daily food intake, meal pattern analysis revealed that they have increased meal size during the dark cycle (Yamashita et al., 2013). However, these effects were offset by no change in meal size during the light cycle as well as no change in meal frequency during the light or dark cycle. Collectively, the findings provide strong evidence that the obese phenotype observed in the OT or OT receptor deficient mice can't be explained by impairments in daily food intake.

The obesity phenotype observed in older OT and OTR deficient mice does not appear in younger mice. For example, there is no difference in body weight between OTR null mice and wild-type mice that are younger [6-7 weeks (Welch et al., 2014) or 10 weeks (Takayanagi et al., 2008)]. While Sun et al. (2019) also found no difference in body weight between 12-week-old OTR null mice and wild-type mice, the OTR null mice did have increased fat mass raising the possibility that differences in body weight may have been observed at a subsequent time. Camerino (2009) also found no difference in body weight between OT null and wild type mice at 8 weeks. It is not clear if differences in background strain, housing conditions and/or thermoregulation may have contributed to the differences in obesity phenotype at specific ages between studies.

One factor that seems contrary to the adult-onset obesity phenotype observed at 8,10 or 16 weeks in OT null mice is that finding that OT null mice tend to have a reduction in muscle regeneration by 12 weeks of age and a significant defect in muscle regeneration and a reduction of both muscle mass and fiber size by 52 weeks of age (Elabd et al., 2014) (characteristic of sarcopenia). These mice tended to have an increased number of adipocytes near the site of muscle regeneration (non-significant) but the hindlimb perimuscular and intramuscular adipose tissue deposition of OT null mice was significantly increased relative to wild-type mice (Elabd et al., 2014). While body weight and body adiposity levels were not reported in these particular mice it is possible that the increase in fat mass compensates for any reduction in lean mass to help maintain the obesity phenotype as OT null mice age and this may help to explain, in part, why the obesity phenotype is not observed in younger OT null mice.

Consistent with a physiological role of endogenous OT in the control of thermogenesis, cold has been found to activate PVN OT neurons (Kasahara et al., 2007) and rostral raphe pallidus OTR (+) cells (Kasahara et al., 2015) as well as to increase expression of OT (hypothalamus) (Yuan et al., 2020) and OTR (BAT and IWAT) (Yuan et al., 2020) and levels of circulating OT (Yuan et al., 2020). One study by Kasahara et al. (2013) reported no change of PVN or SON OT mRNA expression in response to cold but the data were not shown in the study. Mice that lack OT or its receptor do have notable impairments in coldinduced thermogenesis (Kasahara et al., 2007, 2013, 2015; Takayanagi et al., 2008; Xi et al., 2017) and enlarged lipid droplets in IBAT (suggestive of hypo-activity) (Takayanagi et al., 2008) which would potentially contribute to impairments in energy expenditure. Deficits in PVN OT signaling or pharmacological blockage of OT receptors are associated with defects in energy expenditure (Zhang and Cai, 2011; Zhang et al., 2011; Wu et al., 2012). It is well appreciated that BAT thermogenesis is important in the regulation of energy 
expenditure (see Cannon and Nedergaard, 2004; Morrison et al., 2014, for review), but it is not clear if OT's effects on energy expenditure result from BAT thermogenesis. One recent report measured both energy expenditure and BAT thermogenesis in mice with diphtheria toxin-elicited reductions of PVN and SON OT signaling and found reductions in both IBAT temperature and core temperature in response to a cold stimulus, both of which were attenuated by OT pre-treatment $(1 \mathrm{mg} / \mathrm{kg}$, IP). However, there were no alterations in IBAT temperature, core temperature or energy expenditure in mice that were housed at $20-24^{\circ} \mathrm{C}$ (Xi et al., 2017). Similar to the findings by Xi et al. (2017), Kasahara et al. (2013) found a reduction in core temperature in OTR deficient mice that were exposed to cold and also no change in energy expenditure between genotypes at room temperature. Whether their findings point to a more important role of endogenous OT in the control of cold-induced thermogenesis and cold-induced elevations of energy expenditure will remain to be determined. It will be important to determine in future studies if mice with global loss of OT or OT receptors have impairments in both BAT thermogenesis and energy expenditure in response to cold exposure and whether pre-treatment with OT rescues both the impairments in BAT thermogenesis and energy expenditure. This could shed light on whether impairments in BAT thermogenesis may also be linked to impairments in energy expenditure in these animals.

\section{What Receptor Populations Mediate Oxytocin's Effects on Brown Adipose Tissue Thermogenesis and Energy Expenditure?}

Paraventricular nucleus OT neurons are anatomically positioned to control BAT thermogenesis and energy expenditure through polysynaptic projections to IBAT (Oldfield et al., 2002), stellate ganglia (Jansen et al., 1995) [sympathetic ganglia known to innervate IBAT (Oldfield et al., 2002)], as well as WAT depots [EWAT (Shi and Bartness, 2001; Stanley et al., 2010) and IWAT depots (Shi and Bartness, 2001)]. Oldfield et al. (2002) determined that OT was expressed in approximately $10-15 \%$ of PVN neurons that were also co-infected with pseudorabies virus following injections into IBAT. This is in contrast to vasopressin, cocaine and amphetamine-regulated transcript and corticotropin-releasing factor, which were rarely found in PVN OT neurons that were labeled with pseudorabies virus (PRV). Similarly, Jansen et al. (1995) reported that OT was expressed in $10 \%$ of PVN neurons that were co-infected with PRV following injections into stellate ganglia and was also found to be more commonly expressed in PRV (+) neurons than vasopressin (2\%), $\mathrm{CRH}(5 \%)$ and thyrotropin-releasing hormone $(<1 \%)$. Shi and Bartness found that $3.49 \%$ of PVN OT neurons were co-labeled with PRV following PRV injections into WAT (Shi and Bartness, 2001), higher than vasopressin (1.07\%) and tyrosine hydroxylase (2.62\%). In a separate study, Stanley et al. (2010) administered PRV into EWAT and determined that up to $17 \%$ of neurons that expressed PRV also expressed OT compared to approximately 12 , 4 and $26 \%$ for vasopressin, TRH and CRH. Collectively, these findings suggest that OT is one of the more predominant peptides found in outgoing projections to IBAT, IWAT and EWAT.

The extent to which specific OTR populations contribute to BAT thermogenesis and energy expenditure have been examined by determining (1) the effects of localized administration of OT on BAT or core temperature, (2) the activation of regions that express OTRs in response to cold and (3) whether deficits in cold-induced thermogenesis in OTR deficient mice can be restored by re-expression of OTRs into specific CNS sites. Central (3V) administration of OT (which does not differentiate forebrain receptor populations or a forebrain vs. hindbrain site of action) has been found to increase BAT temperature in both mice and rats (Roberts et al., 2017). Noble et al. (2014) extended these findings by showing that OT administration into the hypothalamus (VMH) stimulated energy expenditure in rats, thereby providing more direct evidence in support of a role of VMH OTRs in the control of energy expenditure. In addition, Kasahara showed that cold exposure activates both PVN OXT neurons (Kasahara et al., 2007) and neurons within the dorsomedial nucleus (DMN), an area that expresses OTRs) (Kasahara et al., 2013). Kasahara et al. (2013) also noted that cold also stimulated number of c-Fos $(+)$ neurons (marker of neuronal activation) and that this effect was attenuated in OTR deficient mice. Kasahara et al. (2013) further determined the extent to which OTR signaling within the DMH/VMH was sufficient to elicit BAT thermogenesis by measuring BAT thermogenesis in OTR null mice that received adeno-associated viral vector expression of OTRs in DMH/VMH (Kasahara et al., 2013). They found that OTR expression within the DMH/VMH restored deficits in cold-induced thermogenesis and corrected defects in $\beta 3$ - and $\alpha 2$-adrenoceptor mRNA expression in IBAT. Together, these findings indicate that OTR signaling within the DMH and/or VMH is sufficient to elicit BAT thermogenesis.

The role of OTRs within the midbrain raphe nucleus (median raphe) in the control of body temperature has also been explored. Yoshida et al. (2009) found that direct injections of OT into the median raphe increase body temperature supporting a role of OTRs in this region in the regulation of BAT thermogenesis.

In addition to the midbrain raphe and hypothalamic OTRs, several studies have suggested that hindbrain OTRs may also be important in contributing to OT-elicited BAT thermogenesis. Namely, 4V administration (to target hindbrain OTRs) of OT increases BAT temperature in both rats (Roberts et al., 2017) and mice (Edwards et al., 2021b). In addition, Ong et al. (2017) found that $4 \mathrm{~V}$ administration also increases core temperature in a rat model. Kasahara extended these findings and probed the role of hindbrain OTRs within the rostral raphe pallidus, a region that receives dense innervation from the PVN (Luo et al., 2019), is a component of rostral medullary raphe (RMR) and contains premotor neurons with polysynaptic projections to BAT (Oldfield et al., 2002) and to stellate ganglia that innervate BAT (Jansen et al., 1995). They found that OTR $(+)$ neurons within the rostral raphe pallidus are activated in response to cold exposure (Kasahara et al., 2015). They subsequently addressed if OTRs within the RMR were sufficient to elicit BAT thermogenesis and found that expression of OTRs within the RMR restored deficits in cold-induced thermogenesis and reduced the size of 
the lipid droplets in IBAT tissue to that of control mice (Kasahara et al., 2015). Kasahara et al. (2015) also addressed if OTR in the RMR were necessary for thermoregulation by using an AAV-Cre to delete OTR expression from the RMR of $\mathrm{Oxtr}{ }^{\mathrm{fx} / \mathrm{fx}}$ mice. However, AAV-Cre- elicited deletion of OTRs within the RMR was not effective in restoring impairments in core temperature in response to cold stimulus. The NTS is another hindbrain site that expresses OTRs and has outgoing polysynaptic projections to IBAT (Oldfield et al., 2002) and to stellate ganglia that innervate BAT (Jansen et al., 1995). It is not clear if OTR (+) neurons project to rostral raphe pallidus or directly to the spinal cord. Future studies assessing the impact of NTS OTR gain of function and loss of function will help further delineate the role of NTS OTRs in the control of BAT thermogenesis. Together, these findings suggest that OTRs within multiple hindbrain areas may contribute to the effects of OT on BAT thermogenesis.

In addition to acting at OTRs within the brain, OT may also stimulate BAT thermogenesis and energy expenditure through sympathetic pre-ganglionic OTR-expressing neurons within the spinal cord. Chemogenetic stimulation of OT neurons within the rostral PVN, some of which innervate the thoracic spinal cord, increases c-Fos in thoracic spinal cord cholinergic neurons, boosts energy expenditure and tends to elevate IBAT temperature $(P=0.13)$ (Sutton et al., 2014), although the extent to which these effects are attributed to endogenous OT or another peptide/neurotransmitter within OT neurons has not been determined. Finally, a recent study indicated that OT may also have a direct action through OT on OTRs on brown adipocytes within BAT (Yuan et al., 2020) where OTR expression is found to be upregulated in response to cold (Yuan et al., 2020). Future studies should address if targeted disruption of OTRs within the forebrain hypothalamus, midbrain, hindbrain, spinal cord and BAT decrease both cold-induced thermogenesis and elevations of energy expenditure and elicit adult-onset obesity (similar to that of global OT or OTR deficient mice).

\section{DOES LOCOMOTOR ACTIVITY CONTRIBUTE TO THE ABILITY OF OXYTOCIN TO INCREASE INTERSCAPULAR BROWN ADIPOSE TISSUE TEMPERATURE AND ENERGY EXPENDITURE AND EVOKE WEIGHT LOSS?}

In addition to BAT thermogenesis and heat production, increased locomotor activity is another mechanism to stimulate energy expenditure. However, current data suggest that OT's effects on locomotor activity are inconsistent and appear to vary depending on how it was administered (chronic vs. acute) and, in some cases, whether the animals were lean or obese. We and others have also found that chronic infusions of OT into the lateral ventricle or $3 \mathrm{~V}$, at a dose that was sufficient to reduce body weight and elevate IBAT temperature (16 nmol/day), had no effect on locomotor activity in DIO rats (Deblon et al., 2011; Blevins et al., 2015; Roberts et al.,
2017). In addition, Maejima et al. (2011) have also found that subcutaneous infusion of OT, at a dose that was sufficient to reduce body weight, also had no effect on locomotor activity in DIO mice $(1.6 \mathrm{mg} / \mathrm{kg} /$ day or $\sim 56.4 \mathrm{nmol} /$ day $)$. Based on these collective findings, OT-elicited increases in locomotor activity do not appear to be a major contributor to OT-elicited weight loss in DIO models.

Chemogenetic stimulation of PVN OT neurons or acute CNS or systemic administration of OT has been found to either stimulate, reduce or have no effect on locomotor activity. Sutton et al. (2014) found that chemogenetic activation of PVN OT neurons in Oxytocin-ires-Cre mice increased locomotor activity and energy expenditure and resulted in a tendency (non-significant) toward an increase in subcutaneous IBAT temperature in animals with transponders implanted above the IBAT depot. A recent study by Zhang et al. (2021) found that chemogenetic activation of magnocellular OT neurons that project to the striatum, results in stimulation of locomotor activity over a 20-min period though an OTR-dependent mechanism. Similar to the forementioned chemogenetic studies, one study found that acute administration of OT into the $\mathrm{VMH}$ stimulated physical activity in rats at 1-h post-injection (Noble et al., 2014), but these effects were short-lived and did not following the more prolonged effects of $3 \mathrm{~V}$ or $4 \mathrm{~V}$ OT on IBAT temperature in rats (Roberts et al., 2017) and mice (Roberts et al., 2017; Edwards et al., 2021b). Additional findings indicate that systemic OT was found to (1) reduce methamphetamine-elicited elevations in locomotor activity in rats (Carson et al., 2010), (2) reduce locomotor activity in rats in an OTR-dependent manner (Angioni et al., 2016), or (3) have no significant effect on locomotor activity in female ovariectomized (Iwasa et al., 2019b) or perimenopausal rats (Erdenebayar et al., 2020). Consistent with the earlier reports that systemic OT was able to reduce locomotor activity, CNS administration of OT was also found to block the effects of CNS administration of OTR antagonist to increase locomotor activity. Maejima et al. (2015) also found that intranasal OT, at a dose that reduces food intake, had no effect on locomotor activity while systemic (IP) administration reduced locomotor activity but only during the dark cycle (Maejima et al., 2015). Collectively, these studies suggest that OT results in a brief elevation of locomotor activity, has no effect or reduces locomotor activity. In order to assess if locomotor activity may play a role in OT-elicited elevations of IBAT temperature and/or energy expenditure, IBAT temperature, energy expenditure and locomotor activity should be measured in parallel in the same animals under the same conditions.

\section{IS OXYTOCIN EFFECTIVE AT REDUCING BODY WEIGHT IN MALE AND FEMALE RODENTS?}

Much of the early historical work regarding the effects of OT in the control of food intake has focused on male rodent models but the few studies that have been completed in female rodents have produced somewhat mixed results. One early study reported that 
acute central and peripheral administration of OT reduced food intake similarly in both male and female rats (Benelli et al., 1991). Subsequently, Maejima et al. (2017) examined the effects of OT on body weight and adiposity and found that chronic sc infusions of OT produced similar reductions on body weight and adiposity in male and female DIO C57Bl/6 J mice. In addition, central [intracerebroventricular (ICV)] administration of OT was found effective at reducing food intake and weight gain in female genetically obese Sim 1 haploinsufficient mice but not in female wild-type counterparts (Kublaoui et al., 2008). A recent study by Seelke et al. (2018) reported that intranasal OT may have a more heightened response to reduce weight gain in female DIO prairie voles but the sample size was small. Iwasa et al. (2019b) reported that chronic systemic OT (1x IP administration over 6 days) treatment reduced food intake and body weight in female ovariectomized rats. One recent study by Liu et al. (2020a) indicate that the effectiveness of central OT (ICV) administration to reduce food intake in female rats is influenced by estrous cycle (particularly proestrous) and that estrogen replacement in ovariectomized rats inhibits OT's effects on food intake. In light of these recent findings and the earlier work by Maejima in DIO mice, it will be important to determine if other routes of administration are as impacted by estrous cycle and whether the ability of chronic central or systemic administration of OT to elicit weight loss in female rodents can be optimized if given intermittently throughout the estrous cycle.

The role of endogenous OT in the control of body weight in female rodent models is not clearly understood due, in part, to inconsistent results and data that has largely been generated in male rodents. Previous studies indicate that male OT null mice develop adult-onset obesity at 10 (Kasahara et al., 2007) or 16 weeks (Camerino, 2009) while OTR receptor null mice develop adult-onset obesity at 12 weeks (Takayanagi et al., 2008). While female OT null mice also develop adult onset obesity (Camerino, 2009; Tamma et al., 2009) as early as 8 weeks (Tamma et al., 2009), female OTR deficient mice fail to develop increased body weight relative to control counterparts (Takayanagi et al., 2008; Sun et al., 2019). However, both male and female OT [3-10 months: females; 8-11 months: males] and OTR null mice [3 months: males and females] develop increased fat mass and/or percent fat (Sun et al., 2019). In contrast to the findings from male and female OT null mice, only male Oxytocin-IresCre:Rosa26 ${ }^{\mathrm{iDTR} /+}$ mice with diphtheria toxin-elicited ablations of PVN OT neurons become obese relative to control Rosa26 $6^{\mathrm{iDTR} /+}$ mice (Wu et al., 2012). In contrast to the study from Takayanagi et al. (2008), male $\mathrm{OTR}^{-/-}$mice failed to show increased body weight relative to wild-type controls (Sun et al., 2019) (personal communication with Dr. Tony Yuen and Dr. Mone Zaidi) although it is certainly possible that they would have become obese over time. Further studies will be required in order to provide more clarity on whether differences in genetic background, housing, thermoregulation and/or age might be contributing factors in terms of these apparent differences across studies.

\section{HOW DOES OXYTOCIN IMPACT BODY COMPOSITION?}

Oxytocin may impact body composition through a direct effect on OTRs on adipocytes which express OTRs (Muchmore et al., 1981; Schaffler et al., 2005; Tsuda et al., 2006; Altirriba et al., 2014; Gajdosechova et al., 2014, 2015; Yi et al., 2015) or through an indirect effect through outgoing polysynaptic projections from the PVN to both IWAT (Shi and Bartness, 2001) and EWAT (Shi and Bartness, 2001; Stanley et al., 2010).

Chronic administration (repeated injections or minipump infusions) into the CNS (lateral ventricle, $3 \mathrm{~V}$ ) or systemic OT treatment was found to decrease fat mass relative to baseline fat mass (pre-intervention) or decrease fat mass posttreatment in lean (Deblon et al., 2011) and DIO rats (SpragueDawley $\mathrm{CD}^{\circledR}$ IGS, Long-Evans and Wistar rats) (Deblon et al., 2011; Morton et al., 2012; Blevins et al., 2016; Roberts et al., 2017), DIO C57BL/6J (Roberts et al., 2017) and C57BL/6 mice (Zhang and Cai, 2011; Snider et al., 2019), $d b / d b$ mice (Plante et al., 2015), and ob/ob mice (Altirriba et al., 2014) without producing any significant reductions in lean mass. OT (repeated IP administration) was also found to reduce percent fat mass after only 1 week of treatment and these effects were not associated with any effects on lean mass in lean wild-type mice (Sun et al., 2019) (1 $\mu \mathrm{g} /$ mouse, IP, 3x/week). These more selective effects on fat mass in the absence of any adverse effects on lean mass have also been recapitulated following chronic hindbrain (4V) infusions in DIO C57BL/6J mice (Edwards et al., 2021b).

Oxytocin treatment appears to reduce sc (Maejima et al., 2017), mesenteric (Maejima et al., 2011), EWAT (Maejima et al., 2011; Altirriba et al., 2014) and visceral fat (Maejima et al., 2017) in DIO C57Bl/6J (Maejima et al., 2011) and ob/ob mice (Altirriba et al., 2014) as well as in female ovariectomized Wistar rats (Iwasa et al., 2019b). In addition, OT reduced adipocyte size across several fat depots including sc (Plante et al., 2015; Iwasa et al., 2019b)/inguinal (Edwards et al., 2021b), visceral (Iwasa et al., 2019b), perirenal (Plante et al., 2015), and epicardial (Plante et al., 2015), EWAT (Eckertova et al., 2011; Maejima et al., 2011; Balazova et al., 2016) and mesenteric (Maejima et al., 2011) depots in C57BL/6J (Maejima et al., 2011) and $d b / d b$ mice (Plante et al., 2015) as well as obese Zucker rats (Balazova et al., 2016) or female ovariectomized Wistar rats (Iwasa et al., 2019b). Chronic sc OT treatment also reduced liver weight and fat in hepatocytes in DIO C57BL/6J mice (Maejima et al., 2011) but was found to have no effect on liver triglyceride content in ob/ob mice (Altirriba et al., 2014). In contrast, some studies have reported that chronic systemic or central (4V) OT administration elicited a relative reduction in lean mass compared to vehicle in lean C57BL/6J (Altirriba et al., 2014) and DIO C57BL/6 mice (Snider et al., 2019) as well as in DIO CD IGS rats (Roberts et al., 2017) with or without any relative reductions in fat mass raising the possibility that differential effects may be attributed, in part, to rodent strain, dosing and/or route of administration. While there are exceptions, overall OT treatment 
appears to preferentially reduce fat mass while preserving lean mass across rodent models.

More recent studies have found that more translational routes of administration (intranasal) have also yielded promising effects on body composition in rodents and humans. Chronic intranasal administration (8 IU/kg; $1 \mathrm{x}$ daily over 7 days) tended to reduce carcass fat mass in DIO prairie voles without negatively impacting lean mass (Seelke et al., 2018). Recent translational studies in humans indicate that chronic intranasal OT (24 IU; $4 \mathrm{x}$ daily for 8 weeks) administration also tended to reduce fat mass in obese men and women (Espinoza et al., 2021). Interestingly, it also produced a slight increase in lean mass (Espinoza et al., 2021). These findings are in agreement with previous studies that found both a reduction in relative fat mass (pre- vs. post-intervention) and a slight increase in relative lean mass (pre- vs. post-intervention) following $3 \mathrm{~V}$ administration (16 nmol/day; $\sim 3$-week body comp measurements) (Blevins et al., 2016) and subcutaneous administration (50 nmol/day) in chow-fed and DIO rats (10day body comp measurements). Whether these effects on lean mass are due, in part, to OT's effects on muscle mass and/or bone composition merit further investigation and is discussed further in Section "Mechanism of Action Following Peripheral Administration."

Existing data suggest that OT may impact body composition through increased lipolysis or reduced lipogenesis. In vitro data indicate that OT stimulates glycerol and free fatty acids and/or reduces triglycerides in 3T3-L1 adipocytes (Deblon et al., 2011; Yi et al., 2015). These findings have been recapitulated in vivo in rats (Deblon et al., 2011) and DIO non-human primates (rhesus monkeys) (Blevins et al., 2015). Chronic intranasal OT tended to reduce triglycerides in pre-diabetic obese humans but these effects were not reach statistical significance (Zhang et al., 2013). In addition, chronic ICV infusions of OT (1.6 and $16 \mathrm{nmol} /$ day) increases expression of hormone sensitive lipase (an enzyme linked with lipolysis) in DIO rats (Deblon et al., 2011) in EWAT. In addition, these effects on EWAT were reproduced following chronic sc infusions of OT (50 nmol/day) in $o b / o b$ mice (Altirriba et al., 2014) as well as direct application of OT to 3T3$\mathrm{L} 1$ adipocytes (5 $\mathrm{mm}$ OT over $24 \mathrm{~h}$ ) (Deblon et al., 2011). These findings implicate that these pro-lipolytic effects may occur through both a direct and indirect mechanism. OT was also found to decrease expression of fatty acid synthase (an enzyme linked to lipogenesis) in ob/ob mice (Altirriba et al., 2014), indicating that OT may also decrease lipogenesis. Existing data from animal models suggest that chronic central or systemic OT infusions reduce respiratory quotient in DIO rats (Deblon et al., 2011) and mice (Maejima et al., 2011) compared to vehicle treatment (Deblon et al., 2011; Maejima et al., 2011) or pair-fed animals (Deblon et al., 2011). These effects were also recently translated to humans as OT was also found to reduce respiratory quotient in lean and obese men (Lawson et al., 2015). Collectively, these findings suggest that OT reduces body adiposity and adipocyte size by increasing lipolysis and lipid utilization or oxidation and reducing lipogenesis.

\section{HOW DOES OXYTOCIN IMPACT MUSCLE MASS AND BONE COMPOSITION?}

\section{Effects of Oxytocin on Muscle Mass}

Recent studies implicate a role for OT in the control of thermogenesis in skeletal muscle and muscle regeneration. OTR are expressed in skeletal muscle (Elabd et al., 2014; Gajdosechova et al., 2014, 2015) and in C2C12 mouse myoblast cells (Lee et al., 2008). Existing data suggest that OT may elicit direct effects on OTRs in skeletal muscles as (1) OT was found to stimulate intracellular calcium in $\mathrm{C} 2 \mathrm{C} 12$ mouse myoblast cells and (2) chronic sc infusions of OT stimulate markers of thermogenesis in skeletal muscle (UCP-3 and Atb5a1) (Yuan et al., 2020). In addition to recently recognized role of skeletal muscle thermogenesis, OT has been found to have an important role in muscle regeneration. Loss of function studies show that OT deficient mice have impairments in muscle regeneration @ 12 months of age, but such impairments were not observed in younger animals (3 months of age) (Elabd et al., 2014). These data are consistent with the finding that OTR deficient mice at 3 months of age do not have any impairments in lean mass relative to age-matched wild-type mice (Sun et al., 2019). In addition, hind limb muscles (gastrocnemius and tibialis anterior) in OT deficient mice are associated with reduced muscle mass. The hind limb muscles (quadriceps, gastrocnemius, and tibialis anterior) in OT deficient mice were found to be associated with increased perimuscular and intermuscular adipose tissue (Elabd et al., 2014), findings which are consistent with increased body weight and/or fat mass in this mouse model (Kasahara et al., 2007; Camerino, 2009; Sun et al., 2019).

Of translational importance is that finding that chronic intranasal OT was found to increase lean mass in senior men and women with sarcopenic obesity (discussed in section "Is Oxytocin Effective at Reducing Body Weight in Male and Female Rodents?"). This is consistent with the finding that positive associations have been observed between overnight serum OT concentrations and lean mass in premenopausal women (Schorr et al., 2017). A separate study using animal models provided potential mechanistic insights into these effects. Systemic (sc) treatment with OT (1 $\mu \mathrm{g} / \mathrm{g}$ ) was able to improve muscle regeneration in aged mice to a level that as comparable to that of younger mice (Elabd et al., 2014). In these studies, OT was found to increase (1) the proliferative capacity of old satellite myogenic cells to that of young satellite myogenic cells and (2) the proliferation of primary myogenic progenitor cells. The effects of OT on satellite cells were also found to occur through the MAPK/ERK signaling pathway. Collectively, these findings provide supportive data for future mechanistic studies using intranasal OT in humans with sarcopenia.

\section{Effects of Oxytocin on Bone Composition}

In animal models, OT has been found to have a critical role in maintaining bone mass in both male and female mice as both OT and OTR null mice develop osteoporosis (Tamma et al., 2009) (see Colaianni et al., 2015; McCormack et al., 2020, for 
review). The effects of OT on bone formation are likely due to a direct action of circulating OT as peripheral OTRs as OTRs are expressed on both mouse (Tamma et al., 2009; Colaianni et al., 2012) and human osteoblasts (Copland et al., 1999; Tamma et al., 2009) and osteoclasts (Colucci et al., 2002; Tamma et al., 2009). Furthermore, peripheral administration of OT (two IP injections separated by $12 \mathrm{~h} ; 4 \mu \mathrm{g}$ /mouse) increased TRAPpositive osteoclast formation while central administration was ineffective (Tamma et al., 2009). Peripheral administration has also been found to increase bone mineral density and osteoblast formation, proliferation and differentiation (Tamma et al., 2009). Sun et al. (2019) recently determined that OTRs on osteoblasts were critically important in bone formation by ablating OTRs in osteoblasts using Col2.3Cre mice. Male and female mice that lack OTRs in osteoblasts were found to have low bone mass that resembled that of the OTR null mice (Sun et al., 2019). Mice that lacked OTRs in osteoclasts also developed high bone mass in Acp5Cre mice suggests an important role of OT to increase osteoclastogenesis. Collectively, the effects of OT on bone are thought to occur through both osteoblast differentiation as well as regulation of osteoclast development and function.

While less is known from a mechanistic standpoint about OTelicited regulation of bone mass in humans, human studies do reveal that there is a positive association between bone mass and levels of circulating OT in women (Schorr et al., 2017). While Breuil et al. (2015) did not find this positive association in men, it did find a weak negative association between circulating OT and fracture risk. Breuil et al. $(2011,2014)$ also found that circulating OT levels correlated with osteopenia or osteoporosis in postmenopausal women. In particular, higher circulating levels of OT were associated with high bone mineral density (hip) in women with lower circulating levels of estradiol or higher circulating levels of leptin (Breuil et al., 2014). Similar to what is observed in OT and OTR null mice (Tamma et al., 2009) and in Col2.3Cre mice that lack OTRs in osteoblasts (Sun et al., 2019), humans with low OT serum levels display severe osteoporosis (Breuil et al., 2011). Overall, the effects of OT on bone mineral density in humans appears to be complicated and influenced by sex steroids and metabolic status.

\section{MECHANISM OF ACTION FOLLOWING PERIPHERAL ADMINISTRATION}

While systemic administration of OT may impact body adiposity through a direct effect on white and brown adipocytes, it may reduce food intake, in part, through a direct action on peripheral OTRs in the GI tract (Wu et al., 2003, 2008; Monstein et al., 2004; Ohlsson et al., 2006; Qin et al., 2009; Welch et al., 2009), the enteric nervous system (Monstein et al., 2004; Welch et al., 2009), smooth muscle cells (Monstein et al., 2004; Qin et al., 2009) and the vagus nerve (Welch et al., 2009; Brierley et al., 2021) as well as central OTRs (Ring et al., 2006, 2010; Ho et al., 2014; Iwasaki et al., 2019). Peripheral administration of OTR antagonists that are capable of crossing the BBB stimulate food intake in rodents (Olszewski et al., 2010; Zhang and Cai, 2011) which implicate OTRs within either the CNS or periphery in the control of food intake. Subsequent studies showed that peripheral administration of an OTR antagonist that is not thought to readily cross the $\mathrm{BBB}(\mathrm{L}-371,257)$ produced modest effects to stimulate food intake and body weight gain in chow-fed rats (Ho et al., 2014) suggesting the potential importance of peripheral OTRs in the control of energy balance. Iwasaki et al. $(2014,2019)$ extended these findings in two separate studies and found that the ability of peripheral administration of OT to reduce food intake and elicit Fos (marker of neuronal activation) in the PVN and hindbrain was either attenuated $(0.4 \mathrm{mg} / \mathrm{kg}$, IP) or blocked $(0.2$ and $0.4 \mathrm{mg} / \mathrm{kg}$, IP) in capsaicin-treated and vagotomized mice. Collectively, these findings suggest that OTR signaling through vagal afferents contributes to the effects of peripheral OT administration to reduce food intake. Furthermore, a recent study found that NTS preproglucagon neurons are critical downstream meditators of the feeding suppression in response to systemic OT $(0.4 \mathrm{mg} / \mathrm{kg}$, IP) (Brierley et al., 2021). Together, these findings are consistent with a role of peripheral OTRs in contributing to the effects of systemic OT.

One potential mechanism by which peripheral OT may reduce food intake is through the reduction of gastric emptying. Peripheral OT treatment also decreases gastric emptying in rodents [mice (Welch et al., 2014)/rats (Wu et al., 2003, 2008)] and these effects are attenuated following treatment with an OTR antagonist, Atosiban (Wu et al., 2003, 2008), indicating that these effects are attributed to OTRs. In other cases, systemic administration has been found to have effect on gastric emptying rate [rats (McCann et al., 1989)/humans (Borg et al., 2011)] or a stimulatory effect on gastric motility [rabbits (Li et al., 2007)]. Whether these effects can be attributed, in part, to dosing or species differences awaits further investigation.

Whether the peripheral effects of OT on gastric emptying in rodents is mediated, in part, through activation of peripheral or central OTRs is still not known. CNS administration of OT reduces gastric motility (Rogers and Hermann, 1987; Flanagan et al., 1992) and these effects appear to be mediated by OTRs in the dorsal vagal complex (Rogers and Hermann, 1987). While circulating OT may inhibit gastric motility through a central mechanism these effects may also be mediated through stimulation of OTRs that are expressed in the enteric nervous system (Monstein et al., 2004; Welch et al., 2009) on smooth muscle cells (Monstein et al., 2004; Qin et al., 2009) or nodose ganglion (Welch et al., 2009). As mentioned earlier, systemic OT suppresses food intake, in part, through a vagal mechanism (Iwasaki et al., 2015, 2019) and signaling through NTS preproglucagon (PPG) neurons (Brierley et al., 2021). Future studies that address if the ability of systemic OT to decrease gastric emptying is impaired in capsaicin-treated or vagotomized rodents will help to differentiate a central from peripheral mechanism of action.

Oxytocin may also reduce gastric emptying through the local release of cholecystokinin-8 (CCK-8) and subsequent activation of vagal afferents that innervate the hindbrain. Systemic administration of OT inhibits both gastric emptying and stimulates the release of CCK-8 (Wu et al., 2003, 2008), both of which occur within the time period that peripheral administration of OT reduces food intake (Ho et al., 2014). 
In addition, the effects of systemic OT to reduce gastric emptying are blocked by pretreatment with a CCK1 receptor antagonist, devazepide (Wu et al., 2003, 2008). Furthermore, Iwasaki showed that peripheral administration of OT and CCK8 both activate single vagal afferent neurons (Iwasaki et al., 2014) further supporting both a direct and indirect action of OT to activate vagal relays through activation of CCK1 receptors (Wu et al., 2008). Further studies to determine if the effectiveness of systemic OT to suppress food intake and reduce gastric emptying is attenuated in animals with gastric fistulas that are open (sham feeding; no gastric distension) relative to animals with closed fistulas (real feeding; gastric distension) will be helpful in determining if OT inhibits food intake, in part, by suppressing gastric emptying.

The extent to which circulating OT may inhibit food intake through suppression of the orexigenic signal, ghrelin, is controversial. It has been reported that ghrelin administration centrally can stimulate OT release in rodents (Szabo et al., 2019) and heterocomplex formed by OT receptor and ghrelin receptor can alter OT signaling (Wallace Fitzsimons et al., 2019) (see section "Mechanism of Action Following Peripheral Administration"). One study reported that peripheral OT treatment decreased circulating levels of ghrelin in men (Vila et al., 2009) during a time that is consistent with when OT reduces food intake in rodents (Ho et al., 2014). In contrast, intranasal administration of OT, at a dose that reduced total caloric intake (Lawson et al., 2015), cookie consumption (Ott et al., 2013) and increased circulating levels of OT in other studies (Burri et al., 2008; Striepens et al., 2013), failed to reduce plasma ghrelin. It will be helpful to examine the impact of chronic intranasal OT on circulating levels of ghrelin in the setting of weight loss as this could offer potential mechanistic insights into downstream targets of OT action and additional insights into how OT reduces energy intake in humans, perhaps impacting both homeostatic and reward-based food intake in humans.

\section{EFFECTS OF INTRANASAL OXYTOCIN ON ENERGY HOMEOSTASIS IN RODENT MODELS}

The extent to which circulating OT may enter the CNS remains controversial (Mens et al., 1983; Ermisch et al., 1985; Kendrick et al., 1986; Ring et al., 2006, 2010; Neumann et al., 2013; Ho et al., 2014). Circulating OT may have limited or restricted access to the CNS although some studies suggest that OT does cross the BBB (Mens et al., 1983; Ermisch et al., 1985), and CNS sites that are leaky to BBB (e.g., median eminence and area postrema) might serve as sites of OT uptake. It is also unclear whether transport of OT across the BBB could be hampered in the DIO state as has been proposed for other hormones such as leptin (Banks et al., 1999). Leng and Sabatier (2017) have also raised the possibility that with high peripheral doses, "some OT is likely to enter the brain despite the presence of a very effective blood-brain barrier to OT." Consistent with this, Freeman et al. (2016) found elevated levels of OT within the CSF following the highest intravenous dose of OT used in their study ( $5 \mathrm{IU} / \mathrm{kg}$ or $\sim 29-36.5 \mathrm{IU})$. Lee et al. (2018) also found that deuterated OT given intravenously at a higher dose (80 IU) also resulted in elevated levels within the CSF of rhesus monkeys. In addition, others found that central administration of a non-penetrant OTR antagonist, L371,257 , was able to block the anxiolytic effects of peripheral administration of OT (Ring et al., 2006). In addition, we have also generated data to suggest that hindbrain OTRs contribute, in part, to the satiety response to peripherally administered OT (Ho et al., 2014). In an effort to target the CNS more directly using a minimally invasive route of administration, the majority of clinical trials have administered OT by the intranasal route of administration.

Intranasal administration enables relatively rapid uptake into the CSF of several neuropeptides and hormones, including insulin, vasopressin, and the melanocyte-stimulating hormone, adrenocorticotrophic hormone (4-10), within $30 \mathrm{~min}$ in humans (Born et al., 2002). Intranasal delivery into the cribriform plate rather than the turbinates is one approach that has been proposed to maximize delivery to the CNS and limit uptake into the circulation (Meredith et al., 2015). Intranasal delivery appears to effectively enable OT to enter the CSF in mice, rats, nonhuman primates and humans within 30-45 min post-treatment (Gossen et al., 2012; Neumann et al., 2013; Chang and Platt, 2014; Monte et al., 2014) although others have found that only aerosolized OT (24 IU) reached the CSF of non-human primates (Modi et al., 2014) while intranasal OT @ 24 IU and IV OT @ $48 \mathrm{IU}$ was ineffective. In addition, the extent to which intranasal OT may reach the parenchyma from the CSF is being debated (see Leng and Ludwig, 2016a,b; Leng and Ludwig, 2016c, for review). As Leng and Ludwig (2016a) stated: "several recent studies have looked at the effects of intranasal application of OT on food intake in man. These involve very high doses of OT that raise plasma concentrations to supraphysiological levels; a small amount of the applied OT probably reaches the brain, but whether it does so in effective amounts is uncertain." In addition, the degree to which the OT measured in CSF in response to intranasal OT is due to elevations of exogenous or endogenous OT is also controversial (Ludwig et al., 2013; Neumann et al., 2013; Lee et al., 2018; Smith et al., 2019). Similar to vasopressin (Gouzenes et al., 1998), OT is one of the few hormones that is can stimulate its own release. This can occur, in part, through magnocellular SON (Yamashita et al., 1987; Moos and Richard, 1989) and PVN (Kendrick, 2000) OT autoreceptors following either central or systemic administration. Systemic OT can do this indirectly by activating vagal afferents (Kendrick, 2000; Iwasaki et al., 2015, 2019) where OTRs are expressed (Welch et al., 2009), increasing Fos within PVN OT neurons (Carson et al., 2010; Hicks et al., 2012; Hayashi et al., 2020) and stimulating release of OT within the CNS (Zhang and Cai, 2011) and likely back into the peripheral circulation. These findings have been recently extended to high fat dietfed mice where systemic OT treatment was recently shown to increase Fos within PVN OT neurons (Hayashi et al., 2020) and up-regulate hypothalamic OT mRNA. Similarly, chronic CNS infusions of OT can up-regulate hypothalamic OT mRNA and increase OT levels within the circulation (Miller, 2013). The finding that circulating levels of OT are elevated at 15 
(Striepens et al., 2013), 30 (Striepens et al., 2013), 40 (Monte et al., 2014), 45 (Striepens et al., 2013), 60 min (Striepens et al., 2013; Kirkpatrick et al., 2014; Lee et al., 2018), or 90 min (Kirkpatrick et al., 2014) following intranasal administration in non-human primates (Monte et al., 2014; Lee et al., 2018) and humans (Striepens et al., 2013; Kirkpatrick et al., 2014) raise the possibility that intranasal OT may be either entering the circulation directly or indirectly following the release of endogenous OT into the CNS and peripheral circulation. To address the possibility that the rise in CNS OT in response to intranasal OT might be a result of endogenous release, Smith, Korgan and Young examined the extent to which intranasal OT entered the CNS in OT null mice (Smith et al., 2019). They found that intranasal OT elevated OT levels within the left amygdala as well as blood (Smith et al., 2019). Collectively, these findings extend the previous findings in rodents, non-human primates and humans and suggest that OT is capable of entering the parenchyma following intranasal delivery.

One question is how translatable are metabolic data that are generated in animal models following central or peripheral administration given that OT is largely being administered intranasally in humans. As previously discussed, OT given by peripheral route of administration is likely to act by both peripheral and central OTRs (particularly at higher doses) to inhibit food intake and potentially stimulate thermogenesis and energy expenditure. There is a very limited amount of metabolic data following intranasal administration in rodent models, but it has been found to largely recapitulate the effects of central and peripheral OT to reduce food intake (Maejima et al., 2015) and/or weight gain (Seelke et al., 2018) in mice and DIO prairie voles, respectively. While additional studies tracking the effects of chronic intranasal administration on food intake, thermogenesis and energy expenditure and weight loss need to be undertaken in the rodent model, the data obtained from both central and peripheral administration in animal models appears to translate well to current findings following intranasal administration in animal models.

\section{EFFECTS OF OXYTOCIN ON DYSLIPIDEMIA AND LIPOLYSIS IN RODENT AND NON-HUMAN PRIMATE MODELS}

Both in vitro and in vivo data suggest that OT reduces dyslipidemia and increases lipolysis in rodent and non-human primate models. OT was found to stimulate glycerol in 3T3-L1 adipocytes (Yi et al., 2015), which express OTRs (Schaffler et al., 2005; Yi et al., 2015), indicating that OT stimulates lipolysis in this model through a direct action. In addition, OT also stimulated glycerol release from epididymal fat pads ex vivo (Deblon et al., 2011). ICV OT (1.6 nmol/day) also increased serum glycerol and reduced serum triglycerides following 2-week treatment in rats (Deblon et al., 2011). Chronic 3V infusions (16 nmol/day) over 21-28 days was found to reduce total cholesterol in DIO mice (Roberts et al., 2017) and rats (Blevins et al., 2016; Roberts et al., 2017). Recent findings indicate that in female perimenopausal rats, systemic OT over 12 days was found to reduce triglycerides, LDL and HDL cholesterol (Erdenebayar et al., 2020) raising the possibility that OT could be beneficial in treating hyperlipidemia at the time of menopause or post-menopause. Blevins extended these findings in DIO non-human primates (rhesus monkeys) where chronic $2 \times$ daily subcutaneous injections of OT reduced total cholesterol, Apolipoprotein C-III, high-density lipoprotein, serum triglycerides and increased serum free fatty acids and glycerol following 4-weeks of treatment. It was also associated with a transient reduction of low-density lipoprotein (Blevins et al., 2015). One additional study found that chronic ICV (1.6 nmol/day) infusions of OT stimulated EWAT mRNA expression of lipoprotein lipase (Lpl) and fatty acid transporter (fat) (Deblon et al., 2011), which have both been linked uptake of triglycerides and fatty acids, respectively. While chronic ICV infusions of OT ( $1.6 \mathrm{nmol} /$ day) did not alter enzymes linked to triglyceride storage or lipogenesis (diacylglycerol $O$-acyltransferase homolog 1 , fatty acid synthase, and acetyl-coenzyme A carboxylase alpha), it did stimulate enzymes associated with lipolysis (hormone-sensitive lipase and patatin-like phospholipase domain containing 2) (Deblon et al., 2011). Chronic CNS [ICV, 3V; $16 \mathrm{nmol} /$ day] or systemic OT administration $(1.6 \mathrm{mg} / \mathrm{kg} /$ day or $\sim 56.4 \mathrm{nmol} /$ day $)$ is also associated with decreases in respiratory quotient in DIO rats (Deblon et al., 2011; Blevins et al., 2016) and DIO mice (Maejima et al., 2011) relative to vehicle treated animals (Deblon et al., 2011; Maejima et al., 2011; Blevins et al., 2016) or pair-fed control animals (Deblon et al., 2011). Taken together, these findings suggest that OT-elicited lipolysis and lipid oxidation may contribute to OT-elicited weight loss.

\section{OXYTOCIN RECEPTOR DIMERIZATION}

The OTR is a G protein-coupled receptor (GPCR) that is coupled to the $\mathrm{G} \alpha \mathrm{q}$ alpha subunit $(\mathrm{G} \alpha \mathrm{q})$ or the Gai alpha subunit (Busnelli and Chini, 2018). Given that the OTR is a GPCR it is prone to the formation of heterodimers with other GPCRs that are in close proximity. These heterodimers can impact intracellular signaling pathways, allosteric interactions, endocytosis, biological function and drug effects (Schellekens et al., 2013; Wallace Fitzsimons et al., 2019). This is of particular interest given that OT and ghrelin have opposing actions on food intake and OTRs and the growth hormone secretagogue receptor (GHS-R1a) have overlapping areas of expression in many CNS sites linked to the control of food intake and/or energy expenditure (including the ARC, VMH, NTS, and VTA) (Abizaid et al., 2006; Zigman et al., 2006). Recent studies have provided strong evidence for cross-talk between both receptors and co-expression of OTR/GHSR resulted in an attenuation of OTR-elicited signaling and potential heterocomplex formation (Wallace Fitzsimons et al., 2019).

In addition to ghrelin, the OTR has been found to form homoand heterodimers with other receptors. OTRs and vasopressin V1a and V2 receptors also form homo- and heterodimers (Terrillon et al., 2003). In addition, OTR forms heterocomplexes with dopamine D2 receptors which may potentially contribute 
to anti-anxiety actions of OT within the CeA (de la Mora et al., 2016). Additional studies provide evidence for the presence of dopamine $\mathrm{d} 2$-OTR heteromers located within the ventral and dorsal striatum that may play a role with facilitatory receptor-receptor interactive effects (Romero-Fernandez et al., 2013). Recent studies also indicate that signaling through OT and serotonin $2 \mathrm{~A}$ receptors appears to be impaired through heteroreceptor formation (Chruscicka et al., 2019). The extent to which these homo- or hetero-complexes may contribute to the effects of OT to reduce both anxiety and feeding reward and potentially explain the ability of OT to produce a more pronounced reduction of energy intake in DIO rodents (Deblon et al., 2011; Maejima et al., 2011; Blevins et al., 2016; Roberts et al., 2017; Edwards et al., 2021b) and obese humans (Thienel et al., 2016) will be important questions for future investigation.

\section{DOES OXYTOCIN REDUCE BODY WEIGHT IN OBESE AND OVERWEIGHT HUMANS?}

The beneficial metabolic effects of OT have been recently translated to DIO non-human primates (Blevins et al., 2015) and obese humans (Zhang et al., 2013; Lawson et al., 2015; Thienel et al., 2016). Several small clinical trials conducted in normal weight or overweight/obese men have shown that a single-dose intranasal OT acutely decreased food intake and hedonic eating (Ott et al., 2013; Lawson et al., 2015; Thienel et al., 2016). Large clinical trials of long duration to examine the effectiveness of OT treatment in obesity is lacking but available clinical trial data have revealed beneficial effects of OT on reducing body weight in overweight/obese men and women as well as in an adolescent boy with hypothalamic obesity (Zhang et al., 2013; Hsu et al., 2017). In the first study to show that chronic intranasal OT elicited weight loss in humans, 24 overweight/obese men and women were randomized to receive OT nasal spray 24 international units (IU) four times daily or placebo for 8 weeks (Zhang et al., 2013). OT treatment led to a $8.9 \pm 5.4 \mathrm{~kg}(p<0.001)$ weight loss at the end of the trial and the weight reduction was significantly larger than the placebo at the end of the trial. No adverse events (AEs) were reported during the trial. In addition, in a single case study, chronic intranasal OT was found to reduce obesity and food intake in an obese 13-year-old adolescent following removal of a craniopharyngioma (Hsu et al., 2017), which speaks to the generalized energy homeostatic action of OT independent of obesity etiology. A more recent trial found that chronic intranasal OT (24 IU four times daily for 8 weeks) tended to reduce body adiposity and increase lean mass in a group of older adults with sarcopenia and obesity but failed to produce any changes in BMI (Espinoza et al., 2021). While these studies provided preliminary evidence that OT treatment may have promising metabolic benefits, including reduction of adiposity and/or body weight, sufficiently powered and rigorously designed clinical trials are still needed to confirm the effect of OT seen on energy metabolism. In addition to homeostatic food intake, OT has also been associated with limiting consumption of highly palatable foods in rodent and non-human primate models (for review, see Lawson, 2017; McCormack et al., 2020). These findings also have translated to some extent in humans (Lawson et al., 2015). Several labs have reported that intranasal OT reduced chocolate cookie or biscuit consumption (Ott et al., 2013; Thienel et al., 2016; Burmester et al., 2018). In addition, intranasal OT enhances the cognitive control of food craving in women who viewed images of candies and desserts (Striepens et al., 2016). To evaluate the mechanism for these behavioral findings, Plessow et al. (2018) observed that intranasal OT reduced activation of both homeostatic and feeding reward centers in the CNS, in response to images of highly palatable food during functional MRI. While further studies need to be done to clarify if OT modifies macronutrient preference in humans, these findings together suggest that it may play a role in limiting consumption of stress- or emotional-eating of food high in sugar or fat.

Thus, while several small clinical trials conducted in normal weight or overweight/obese men have now shown that a singledose intranasal OT acutely decreased calorie intake (Lawson et al., 2015; Thienel et al., 2016), hedonic eating (Ott et al., 2013; Lawson et al., 2015; Thienel et al., 2016) and food craving (Striepens et al., 2016) it is still unclear if these findings would hold up in a paradigm of chronic administration or if they would be correlated with clinically meaningful weight loss. While the one study by Zhang et al. (2013) found that chronic intranasal OT elicited weight loss in overweight/obese humans, the mechanism of action of OT remains unexplored (e.g., associated with an increase in energy expenditure and/or decrease in appetite/food intake). Sufficiently powered, rigorously designed clinical trials are needed to examine the efficacy, tolerability and safety of OT use in humans. Based on our preclinical data and available clinical observations, we argue that OT holds promise as an appealing, non-invasive strategy to combat obesity though its CNS action on regulating appetite (Striepens et al., 2013; Freeman et al., 2016) and/or energy expenditure.

\section{TRANSLATIONAL POTENTIAL}

Intravenous/intramuscular OT is FDA-approved and has a long track record of clinical use in parturition (Vallera et al., 2017). Intranasal OT has been used clinically for over 50 years (most commonly in the field of psychiatry) and has an excellent safety profile (MacDonald et al., 2011). A systematic review of 38 RTCs conducted between 1990 and 2010 on over 1500 individuals $(79 \%$ men $)$ showed that OT was not associated with adverse outcomes when delivered at doses of 18-40 IU for short term use in controlled research settings (MacDonald et al., 2011). Mild side effects including drowsiness/sleepiness, calm/relaxed/comfortable, lightheadedness, and feeling of anxious/worried were reported by 279 out of 1529 participants (18\%). Since then, longer term studies have been conducted and continued to demonstrate an excellent safety profile of intranasal OT (Tachibana et al., 2013; Zhang et al., 2013; Hsu et al., 2017; Cai et al., 2018). As mentioned earlier, the pharmacokinetics of intranasal OT administration have been investigated. Striepens et al. (2013) showed that, in subjects who received 24 IU of OT intranasally (or placebo), OT levels increased significantly in 
plasma at 15, 30, 45, and $60 \mathrm{~min}$ after administration, and in cerebrospinal fluid (CSF) at 75 min when the plasma level began to decline. In another study by Gossen et al. (2012), following 26 IU of single intranasal OT administration in eight men plasma OT concentrations increased over a period of $210 \mathrm{~min}$, reaching a peak at $30 \mathrm{~min}$. Lawson et al. (2015) previously showed that a single-dose (24 IU) intranasal OT acutely decreases food intake; Zhang et al. (2013) reported that 24 IU given QID over 8 weeks reduced body weight in overweight/obese men and women. The 40 IU dose has been used in clinical trials for up to approximately 10 weeks at a frequency of once daily and was well tolerated (van Zuiden et al., 2017; Flanagan et al., 2018).

As discussed above, OT may increase BAT thermogenesis through its action in the modulation of CNS sympathetic output and on sympathetic pre-ganglionic OTR-expressing neurons within the spinal cord to increase SNS outflow (see section "Source and Functions of Oxytocin"). Collectively, this may adversely affect cardiac function and hamper its translational potential (Greenfield et al., 2009; Kievit et al., 2013) given the high prevalence of hypertension and cardiovascular disease among individuals who are overweight or obese (Nguyen et al., 2008). However, studies in animals have generated mixed results demonstrating an increase, decrease or no change in blood pressure (Petersson et al., 1996; Nation et al., 2010; Maejima et al., 2011; Ludwig et al., 2013; Yosten and Samson, 2014) or heart rate (Petersson et al., 1996; Yang et al., 2009; Yoshida et al., 2009; Nation et al., 2010; Maejima et al., 2011; Ludwig et al., 2013; Hicks et al., 2014; Plante et al., 2015) depending on route of OT administration and species studied (for review, see Petersson, 2002; Gutkowska and Jankowski, 2012). Studies using intranasal OT in humans have not reported adverse side effects on heart rate (Burri et al., 2008; Kirkpatrick et al., 2014; Lawson et al., 2015), blood pressure (Kirkpatrick et al., 2014; Lawson et al., 2015) or cardiovascular dysfunction (Zhang et al., 2013) in men (Burri et al., 2008; Zhang et al., 2013; Kirkpatrick et al., 2014; Lawson et al., 2015) and non-pregnant women (Zhang et al., 2013; Kirkpatrick et al., 2014). The sample size of these studies was small, and the duration of treatment was short (up to 8 weeks). Therefore, it will be prudent to carefully monitor cardiovascular outcomes such as heart rate and blood pressure with chronic OT treatment in future studies.

\section{CONCLUSION}

Pre-clinical data in rodents and non-human primates suggest that OT elicits weight loss, in part, by both central and peripheral mechanisms to reduce food intake (homeostatic and hedonic feeding) and impact energy expenditure in the absence of visceral illness or tolerance. While there is much enthusiasm over the potential use of OT as a therapeutic strategy to treat eating disorders and obesity, we await the results of ongoing clinical trials in obese humans for additional confirmation of its feasibility as a long-term weight loss strategy and assessment of adverse side effects. There is an ongoing need to identify an optimal dose, frequency, and duration of administration and to examine the dose-response effects of intranasal OT on body weight and adiposity in individuals with obesity.

Combination drug treatment has demonstrated impressive efficacy in inducing weight loss [(Frias et al., 2017; Chepurny et al., 2018)] (for review, see Rodgers et al., 2012). We think OT may be more optimal as an adjunct therapy for obesity rather than a monotherapy. It is clear that OT is effective as a monotherapy to elicit weight loss in DIO rodents (Deblon et al., 2011; Maejima et al., 2011, 2017; Zhang and Cai, 2011; Zhang et al., 2011; Morton et al., 2012; Blevins et al., 2016; Roberts et al., 2017; Edwards et al., 2021b), non-human primates (Blevins et al., 2015) and humans (Zhang et al., 2013), but these effects (pre- vs. post-intervention) appear to be modest even after sustained treatments that last $4-8$ weeks $[\approx 4.9 \%$ in DIO mice (Roberts et al., 2017), 8.7\% in DIO rats (Roberts et al., 2017), 3.3\% in DIO rhesus monkeys (Blevins et al., 2015) and 9.3\% humans based on results from a proof of concept study with short duration and small sample size (Zhang et al., 2013)]. The average weight loss with the currently FDA approved medications (i.e., orlistat, liraglutide, naltrexone/bupropion, phentermine/topiramate, semaglutide) ranges between 5 and 14.9\% (Allison et al., 2012; Apovian et al., 2015; Bray et al., 2018; Enebo et al., 2021).

Long-term efficacy of OT treatment for obesity remains to be established. The effect of OT on thermogenesis, appetite and stress reduction may offer unique properties that current therapies do not have. OT as an adjunct therapy for obesity is also worth exploring. For instance, pre-clinical and clinical studies indicate that OT in combination with the opioid antagonist, naltrexone, is an effective strategy to reduce food intake (animals, humans) as well as body weight (humans). Peripheral (intravenous) administration of OT and naltrexone was recently found to be effective at reducing palatable $10 \%$ sucrose solutions as well as intake of a high fat/high sugar diet in rats (Head et al., 2021). Intranasal OT was also found to be effective at reducing hyperphagia and maintaining weight loss when given in combination with the opioid antagonist, naltrexone, to a 13-year-old adolescent male with craniopharyngioma related hypothalamic obesity (Hsu et al., 2017). Thus, the combination of OT with other therapies that act, in part to reduce food intake (hedonic and/or homeostatic feeding) and increase energy expenditure may act in an additive mechanism to elicit greater weight loss than either treatment alone.

\section{AUTHOR CONTRIBUTIONS}

JN helped write and edit the manuscript and she also helped generate Figure 1. JT helped write and edit the manuscript. JB provided feedback on the figure and helped write and edit the manuscript. All authors contributed to the article and approved the submitted version. 


\section{ACKNOWLEDGMENTS}

This material was based upon work supported by the Office of Research and Development, Medical Research Service, Department of Veterans Affairs (VA). This work was also supported by the VA Merit Review Award 5I01BX004102, from

\section{REFERENCES}

Abizaid, A., Liu, Z. W., Andrews, Z. B., Shanabrough, M., Borok, E., Elsworth, J. D., et al. (2006). Ghrelin modulates the activity and synaptic input organization of midbrain dopamine neurons while promoting appetite. J. Clin. Investig. 116, 3229-3239. doi: 10.1172/JCI29867

Allison, D. B., Gadde, K. M., Garvey, W. T., Peterson, C. A., Schwiers, M. L., Najarian, T., et al. (2012). Controlled-release phentermine/topiramate in severely obese adults: a randomized controlled trial (EQUIP). Obesity 20, 330-342. doi: 10.1038/oby.2011.330

Altirriba, J., Poher, A. L., Caillon, A., Arsenijevic, D., Veyrat-Durebex, C., Lyautey, J., et al. (2014). Divergent effects of oxytocin treatment of obese diabetic mice on adiposity and diabetes. Endocrinology 155, 4189-4201. doi: 10.1210/en.20141466

Amico, J. A., Vollmer, R. R., Cai, H. M., Miedlar, J. A., and Rinaman, L. (2005). Enhanced initial and sustained intake of sucrose solution in mice with an oxytocin gene deletion. Am. J. Physiol. Regul. Integr. Comp. Physiol. 289, R1798-R1806.

Angioni, L., Cocco, C., Ferri, G. L., Argiolas, A., Melis, M. R., and Sanna, F. (2016). Involvement of nigral oxytocin in locomotor activity: a behavioral, immunohistochemical and lesion study in male rats. Horm. Behav. 83, 23-38. doi: 10.1016/j.yhbeh.2016.05.012

Antunes, J. L., and Zimmerman, E. A. (1978). The hypothalamic magnocellular system of the rhesus monkey: an immunocytochemical study. J. Comp. Neurol. 181, 539-565.

Apovian, C. M., Aronne, L. J., Bessesen, D. H., McDonnell, M. E., Murad, M. H., Pagotto, U., et al. (2015). Pharmacological management of obesity: an endocrine Society clinical practice guideline. J. Clin. Endocrinol. Metab. 100, 342-362.

Arletti, R., Benelli, A., and Bertolini, A. (1989). Influence of oxytocin on feeding behavior in the rat. Peptides 10, 89-93.

Arletti, R., Benelli, A., and Bertolini, A. (1990). Oxytocin inhibits food and fluid intake in rats. Physiol. Behav. 48, 825-830.

Balazova, L., Krskova, K., Suski, M., Sisovsky, V., Hlavacova, N., Olszanecki, R., et al. (2016). Metabolic effects of subchronic peripheral oxytocin administration in lean and obese zucker rats. J. Physiol. Pharmacol. 67, 531-541.

Bales, K. L., Perkeybile, A. M., Conley, O. G., Lee, M. H., Guoynes, C. D., Downing, G. M., et al. (2013). Chronic intranasal oxytocin causes long-term impairments in partner preference formation in male prairie voles. Biol. Psychiatry 74, 180-188. doi: 10.1016/j.biopsych.2012.08.025

Banks, W. A., DiPalma, C. R., and Farrell, C. L. (1999). Impaired transport of leptin across the blood-brain barrier in obesity. Peptides 20, 1341-1345.

Bartz, J., Simeon, D., Hamilton, H., Kim, S., Crystal, S., Braun, A., et al. (2011). Oxytocin can hinder trust and cooperation in borderline personality disorder. Soc. Cogn. Affect. Neurosci. 6, 556-563.

Baskin, D. G., and Bastian, L. S. (2010). "Immuno-laser capture microdissection of rat brain neruons for real time quantitative PCR," in Immunocytochemical methods and protocols, Methods in Molecular Biology, eds C. Oliver and M. C. Jamur (New York, NY: Humana Press), 219-230. doi: 10.1007/978-1-59745324-0_23

Baskin, D. G., Kim, F., Gelling, R. W., Russell, B. J., Schwartz, M. W., Morton, G. J., et al. (2010). A new oxytocin-saporin cytotoxin for lesioning oxytocinreceptive neurons in the rat hindbrain. Endocrinology 151, 4207-4213. doi: 10.1210/en.2010-0295

Beier, K. T., Steinberg, E. E., DeLoach, K. E., Xie, S., Miyamichi, K., Schwarz, L., et al. (2015). Circuit architecture of VTA dopamine neurons revealed by systematic input-output mapping. Cell 162, 622-634. doi: 10.1016/j.cell.2015. 07.015 the United States Department of Veterans Affairs Biomedical Laboratory Research and Development Service and NIH 5R01DK115976 grant to JB. In addition, we acknowledge JN for her technical assistance with Figure 1. The contents do not represent the views of the United States Department of Veterans Affairs or the United States Government.

Benelli, A., Bertolini, A., and Arletti, R. (1991). Oxytocin-induced inhibition of feeding and drinking: no sexual dimorphism in rats. Neuropeptides 20, 57-62. doi: 10.1016/0143-4179(91)90040-p

Bergum, D., Lonnee, H., and Hakli, T. F. (2009). Oxytocin infusion: acute hyponatraemia, seizures and coma. Acta Anaesth. Scand. 53, 826-827. doi: 10.1111/j.1399-6576.2009.01964.x

Blevins, J. E., and Baskin, D. G. (2015). Translational and therapeutic potential of oxytocin as an anti-obesity strategy: insights from rodents, nonhuman primates and humans. Physiol. Behav. 152(Pt B), 438-449. doi: 10.1016/j.physbeh.2015. 05.023

Blevins, J. E., Eakin, T. J., Murphy, J. A., Schwartz, M. W., and Baskin, D. G. (2003). Oxytocin innervation of caudal brainstem nuclei activated by cholecystokinin. Brain Res. 993, 30-41. doi: 10.1016/j.brainres.2003.08.036

Blevins, J. E., Graham, J. L., Morton, G. J., Bales, K. L., Schwartz, M. W., Baskin, D. G., et al. (2015). Chronic oxytocin administration inhibits food intake, increases energy expenditure, and produces weight loss in fructose-fed obese rhesus monkeys. Am. J. Physiol. Regul. Integr. Comp. Physiol. 308, R431-R438. doi: 10.1152/ajpregu.00441.2014

Blevins, J. E., and Ho, J. M. (2013). Role of oxytocin signaling in the regulation of body weight. Rev. Endocrine Metab. Disord. 14, 311-329.

Blevins, J. E., Morton, G. J., Williams, D. L., Caldwell, D. W., Bastian, L. S., Wisse, B. E., et al. (2009). Forebrain melanocortin signaling enhances the hindbrain satiety response to CCK-8. Am. J. Physiol. Regul. Integr. Comp. Physiol. 296, R476-R484. doi: 10.1152/ajpregu.90544.2008

Blevins, J. E., Schwartz, M. W., and Baskin, D. G. (2004). Evidence that paraventricular nucleus oxytocin neurons link hypothalamic leptin action to caudal brain stem nuclei controlling meal size. Am. J. Physiol. Regul. Integr. Comp. Physiol. 287, R87-R96. doi: 10.1152/ajpregu.00604.2003

Blevins, J. E., Thompson, B. W., Anekonda, V. T., Ho, J. M., Graham, J. L., Roberts, Z. S., et al. (2016). Chronic CNS oxytocin signaling preferentially induces fat loss in high fat diet-fed rats by enhancing satiety responses and increasing lipid utilization. Am. J. Physiol. Reg. I 310, R640-R58. doi: 10.1152/ajpregu.00220. 2015

Blouet, C., Jo, Y. H., Li, X., and Schwartz, G. J. (2009). Mediobasal hypothalamic leucine sensing regulates food intake through activation of a hypothalamusbrainstem circuit. J. Neurosci. 29, 8302-8311. doi: 10.1523/JNEUROSCI.166809.2009

Boccia, M. L., Panicker, A. K., Pedersen, C., and Petrusz, P. (2001). Oxytocin receptors in non-human primate brain visualized with monoclonal antibody. Neuroreport 12, 1723-1726. doi: 10.1097/00001756-200106130-00041

Boccia, M. L., Petrusz, P., Suzuki, K., Marson, L., and Pedersen, C. A. (2013). Immunohistochemical localization of oxytocin receptors in human brain. Neuroscience 253, 155-164.

Borg, J., Simren, M., and Ohlsson, B. (2011). Oxytocin reduces satiety scores without affecting the volume of nutrient intake or gastric emptying rate in healthy subjects. Neurogastroenterol. Motil. 23, 56.e5-61.e5.

Born, J., Lange, T., Kern, W., McGregor, G. P., Bickel, U., and Fehm, H. L. (2002). Sniffing neuropeptides: a transnasal approach to the human brain. Nat. Neurosci. 5, 514-516. doi: 10.1038/nn849

Braude, R., and Mitchell, K. G. (1952). Observations on the relationship between oxytocin and adrenaline in milk ejection in the sow. J. Endocrinol. 8, 238-241. doi: $10.1677 /$ joe. 0.0080238

Bray, G. A., Heisel, W. E., Afshin, A., Jensen, M. D., Dietz, W. H., Long, M., et al. (2018). The science of obesity management: an endocrine society scientific statement. Endocr. Rev. 39, 79-132.

Breuil, V., Amri, E. Z., Panaia-Ferrari, P., Testa, J., Elabd, C., AlbertSabonnadiere, C., et al. (2011). Oxytocin and bone remodelling: relationships with neuropituitary hormones, bone status and body composition. Joint Bone Spine 78, 611-615. doi: 10.1016/j.jbspin.2011.02.002 
Breuil, V., Fontas, E., Chapurlat, R., Panaia-Ferrari, P., Yahia, H. B., Faure, S., et al. (2015). Oxytocin and bone status in men: analysis of the MINOS cohort. Osteoporos. Int. 26, 2877-2882. doi: 10.1007/s00198-015-3201-3

Breuil, V., Panaia-Ferrari, P., Fontas, E., Roux, C., Kolta, S., Eastell, R., et al. (2014). Oxytocin, a new determinant of bone mineral density in post-menopausal women: analysis of the OPUS cohort. J. Clin. Endocrinol. Metab. 99, E634-E641. doi: $10.1210 /$ jc. $2013-4126$

Brierley, D. I., Holt, M. K., Singh, A., de Araujo, A., McDougle, M., Vergara, M., et al. (2021). Central and peripheral GLP-1 systems independently suppress eating. Nat. Metab. 3, 258-273.

Brownstein, M. J., Russell, J. T., and Gainer, H. (1980). Synthesis, transport, and release of posterior pituitary hormones. Science 207, 373-378.

Burmester, V., Higgs, S., and Terry, P. (2018). Rapid-onset anorectic effects of intranasal oxytocin in young men. Appetite 130, 104-109. doi: 10.1016/j.appet. 2018.08.003

Burri, A., Heinrichs, M., Schedlowski, M., and Kruger, T. H. (2008). The acute effects of intranasal oxytocin administration on endocrine and sexual function in males. Psychoneuroendocrinology 33, 591-600. doi: 10.1016/j.psyneuen.2008. 01.014

Busnelli, M., and Chini, B. (2018). Molecular basis of oxytocin receptor signalling in the brain: what we know and what we need to know. Curr. Top. Behav. Neurosci. 35, 3-29. doi: 10.1007/7854_2017_6

Cai, Q., Feng, L., and Yap, K. Z. (2018). Systematic review and meta-analysis of reported adverse events of long-term intranasal oxytocin treatment for autism spectrum disorder. Psychiatry Clin. Neurosci. 72, 140-151. doi: 10.1111/pcn. 12627

Caldwell, J. D., Jirikowski, G. F., Greer, E. R., Stumpf, W. E., and Pedersen, C. A. (1988). Ovarian steroids and sexual interaction alter oxytocinergic content and distribution in the basal forebrain. Brain Res. 446, 236-244. doi: 10.1016/00068993(88)90882-7

Camerino, C. (2009). Low sympathetic tone and obese phenotype in oxytocindeficient mice. Obesity 17, 980-984. doi: 10.1038/oby.2009.12

Cannon, B., and Nedergaard, J. (2004). Brown adipose tissue: function and physiological significance. Physiol. Rev. 84, 277-359.

Carson, D. S., Hunt, G. E., Guastella, A. J., Barber, L., Cornish, J. L., Arnold, J. C., et al. (2010). Systemically administered oxytocin decreases methamphetamine activation of the subthalamic nucleus and accumbens core and stimulates oxytocinergic neurons in the hypothalamus. Addict. Biol. 15, 448-463. doi: 10.1111/j.1369-1600.2010.00247.x

Castel, M., and Morris, J. F. (1988). The neurophysin-containing innervation of the forebrain of the mouse. Neuroscience 24, 937-966. doi: 10.1016/0306-4522(88) 90078-4

Cechetto, D. F., and Saper, C. B. (1988). Neurochemical organization of the hypothalamic projection to the spinal cord in the rat. J. Comp. Neurol. 272, 579-604. doi: 10.1002/cne.902720410

Chang, S. W., and Platt, M. L. (2014). Oxytocin and social cognition in rhesus macaques: implications for understanding and treating human psychopathology. Brain Res. 1580, 57-68. doi: 10.1016/j.brainres.2013.11.006

Chepurny, O. G., Bonaccorso, R. L., Leech, C. A., Wollert, T., Langford, G. M., Schwede, F., et al. (2018). Chimeric peptide EP45 as a dual agonist at GLP-1 and NPY2R receptors. Sci. Rep. 8:3749.

Chruscicka, B., Wallace Fitzsimons, S. E., Borroto-Escuela, D. O., Druelle, C., Stamou, P., Nally, K., et al. (2019). Attenuation of oxytocin and serotonin $2 \mathrm{~A}$ receptor signaling through novel heteroreceptor formation. ACS Chem. Neurosci. 10, 3225-3240. doi: 10.1021/acschemneuro.8b00665

Colaianni, G., Sun, L., Benedetto, A. Di, Tamma, R., Zhu, L. L., Cao, J., et al. (2012). Bone marrow oxytocin mediates the anabolic action of estrogen on the skeleton. J. Biol. Chem. 287, 29159-29167. doi: 10.1074/jbc.M112.365049

Colaianni, G., Sun, L., Zaidi, M., and Zallone, A. (2015). The "love hormone" oxytocin regulates the loss and gain of the fat-bone relationship. Front. Endocrinol. 6:79. doi: 10.3389/fendo.2015.00079

Colucci, S., Colaianni, G., Mori, G., Grano, M., and Zallone, A. (2002). Human osteoclasts express oxytocin receptor. Biochem. Biophys. Res. Commun. 297, 442-445.

Copland, J. A., Ives, K. L., Simmons, D. J., and Soloff, M. S. (1999). Functional oxytocin receptors discovered in human osteoblasts. Endocrinology 140, 43714374. doi: 10.1210 /endo.140.9.7130
Cornier, M. A., Dabelea, D., Hernandez, T. L., Lindstrom, R. C., Steig, A. J., Stob, N. R., et al. (2008). The metabolic syndrome. Endocrine Rev. 29, 777-822.

Daniels, D., and Flanagan-Cato, L. M. (2000). Functionally-defined compartments of the lordosis neural circuit in the ventromedial hypothalamus in female rats. J. Neurobiol. 45, 1-13.

de la Mora, M. P., Perez-Carrera, D., Crespo-Ramirez, M., Tarakanov, A., Fuxe, K., and Borroto-Escuela, D. O. (2016). Signaling in dopamine D2 receptoroxytocin receptor heterocomplexes and its relevance for the anxiolytic effects of dopamine and oxytocin interactions in the amygdala of the rat. Biochim. Biophys. Acta 1862, 2075-2085. doi: 10.1016/j.bbadis.2016.07.004

Deblon, N., Veyrat-Durebex, C., Bourgoin, L., Caillon, A., Bussier, A. L., Petrosino, S., et al. (2011). Mechanisms of the anti-obesity effects of oxytocin in diet-induced obese rats. PLoS One 6:e25565. doi: 10.1371/journal.pone.002 5565

den Hertog, C. E., de Groot, A. N., and van Dongen, P. W. (2001). History and use of oxytocics. Eur. J. Obstetr. Gynecol. Reproduct. Biol. 94, 8-12.

Dierickx, K., and Vandesande, F. (1977). Immunocytochemical localization of the vasopressinergic and the oxytocinergic neurons in the human hypothalamus. Cell Tissue Res. 184, 15-27. doi: 10.1007/BF00220524

Eckel, R. H., Grundy, S. M., and Zimmet, P. Z. (2005). The metabolic syndrome. Lancet 365, 1415-1428.

Eckertova, M., Ondrejcakova, M., Krskova, K., Zorad, S., and Jezova, D. (2011). Subchronic treatment of rats with oxytocin results in improved adipocyte differentiation and increased gene expression of factors involved in adipogenesis. Br. J. Pharmacol. 162, 452-463. doi: 10.1111/j.1476-5381.2010. 01037.x

Edwards, M. M., Nguyen, H. K., Herbertson, A. J., Dodson, A. D., Wietecha, T., Wolden-Hanson, T., et al. (2021b). Chronic hindbrain administration of oxytocin elicits weight loss in male diet-induced obese mice. Am. J. Physiol. Regul. Integr. Comp. Physiol. 320, R471-R487.

Edwards, M. M., Nguyen, H. K., Dodson, A. D., Herbertson, A. J., Wietecha, T. A., Wolden-Hanson, T., et al. (2021a). Effects of combined oxytocin and beta-3 receptor agonist (CL 316243) treatment on body weight and adiposity in male diet-induced obese rats. Front. Physiol. 12:725912. doi: 10.3389/fphys. 2021.725912

Elabd, C., Cousin, W., Upadhyayula, P., Chen, R. Y., Chooljian, M. S., Li, J., et al. (2014). Oxytocin is an age-specific circulating hormone that is necessary for muscle maintenance and regeneration. Nat. Commun. 5:4082. doi: 10.1038/ ncomms 5082

Enebo, L. B., Berthelsen, K. K., Kankam, M., Lund, M. T., Rubino, D. M., Satylganova, A., et al. (2021). Safety, tolerability, pharmacokinetics, and pharmacodynamics of concomitant administration of multiple doses of cagrilintide with semaglutide $2.4 \mathrm{mg}$ for weight management: a randomised, controlled, phase $1 \mathrm{~b}$ trial. Lancet 397, 1736-1748. doi: 10.1016/S0140-6736(21) 00845-X

Erdenebayar, O., Kato, T., Kawakita, T., Kasai, K., Kadota, Y., Yoshida, K., et al. (2020). Effects of peripheral oxytocin administration on body weight, food intake, adipocytes, and biochemical parameters in peri- and postmenopausal female rats. Endocrine J. 68, 7-16. doi: 10.1507/endocrj.EJ19-0586

Ermisch, A., Barth, T., Ruhle, H. J., Skopkova, J., Hrbas, P., and Landgraf, R. (1985). On the blood-brain barrier to peptides: accumulation of labelled vasopressin, DesGlyNH2-vasopressin and oxytocin by brain regions. Endocrinol. Exp. 19, 29-37.

Espinoza, S. E., Lee, J. L., Wang, C. P., Ganapathy, V., MacCarthy, D., Pascucci, C., et al. (2021). Intranasal oxytocin improves lean muscle mass and lowers LDL cholesterol in older adults with sarcopenic obesity: a pilot randomized controlled trial. J. Am. Med. Dir. Assoc. 22, 1877.e2-1882.e2. doi: 10.1016/j. jamda.2021.04.015

Fenselau, H., Campbell, J. N., Verstegen, A. M., Madara, J. C., Xu, J., Shah, B. P., et al. (2017). A rapidly acting glutamatergic ARC-> PVH satiety circuit postsynaptically regulated by alpha-MSH. Nat. Neurosci. 20, 42-51. doi: 10 . 1038/nn.4442

Finkelstein, E. A., Trogdon, J. G., Cohen, J. W., and Dietz, W. (2009). Annual medical spending attributable to obesity: payer-and service-specific estimates. Health Affairs 28, w822-w831. doi: 10.1377/hlthaff.28.5.w822

Flanagan, J. C., Sippel, L. M., Wahlquist, A., Moran-Santa Maria, M. M., and Back, S. E. (2018). Augmenting Prolonged Exposure therapy for PTSD with 
intranasal oxytocin: a randomized, placebo-controlled pilot trial. J. Psychiatr. Res. 98, 64-69. doi: 10.1016/j.jpsychires.2017.12.014

Flanagan, L. M., Olson, B. R., Sved, A. F., Verbalis, J. G., and Stricker, E. M. (1992). Gastric motility in conscious rats given oxytocin and an oxytocin antagonist centrally. Brain Res. 578, 256-260. doi: 10.1016/0006-8993(92)90255-8

Flanagan-Cato, L. M., Calizo, L. H., and Daniels, D. (2001). The synaptic organization of VMH neurons that mediate the effects of estrogen on sexual behavior. Hormon. Behav. 40, 178-182.

Fosgerau, K., Raun, K., Nilsson, C., Dahl, K., and Wulff, B. S. (2014). Novel alphaMSH analog causes weight loss in obese rats and minipigs and improves insulin sensitivity. J. Endocrinol. 220, 97-107. doi: 10.1530/JOE-13-0284

Freeman, S. M., Inoue, K., Smith, A. L., Goodman, M. M., and Young, L. J. (2014). The neuroanatomical distribution of oxytocin receptor binding and mRNA in the male rhesus macaque (Macaca mulatta). Psychoneuroendocrinology 45, 128-141. doi: 10.1016/j.psyneuen.2014.03.023

Freeman, S. M., Ngo, J., Singh, B., Masnaghetti, M., Bales, K. L., and Blevins, J. E. (2018). Effects of chronic oxytocin administration and diet composition on oxytocin and vasopressin 1a receptor binding in the rat brain. Neuroscience 392, 241-251. doi: 10.1016/j.neuroscience.2018.07.037

Freeman, S. M., Samineni, S., Allen, P. C., Stockinger, D., Bales, K. L., Hwa, G. G., et al. (2016). Plasma and CSF oxytocin levels after intranasal and intravenous oxytocin in awake macaques. Psychoneuroendocrinology 66, 185-194. doi: 10. 1016/j.psyneuen.2016.01.014

Freund-Mercier, M. J., and Stoeckel, M. E. (1995). Somatodendritic autoreceptors on oxytocin neurones. Adv. Exp. Med. Biol. 395, 185-194.

Freund-Mercier, M. J., Stoeckel, M. E., and Klein, M. J. (1994). Oxytocin receptors on oxytocin neurones: histoautoradiographic detection in the lactating rat. J. Physiol. 480(Pt 1), 155-161.

Frias, J. P., Bastyr, E. J., Vignati, L., Tschop, M. H., Schmitt, C., Owen, K., et al. (2017). The sustained effects of a dual GIP/GLP-1 receptor agonist, NNC00902746, in patients with Type 2 diabetes. Cell Metab. 26, 343-345. doi: 10.1016/j. cmet.2017.07.011

Gajdosechova, L., Krskova, K., Olszanecki, R., and Zorad, S. (2015). Differential regulation of oxytocin receptor in various adipose tissue depots and skeletal muscle types in obese Zucker rats. Hormone Metab. Res. 47, 600-604. doi: 10.1055/s-0034-1395677

Gajdosechova, L., Krskova, K., Segarra, A. B., Spolcova, A., Suski, M., Olszanecki, R., et al. (2014). Hypooxytocinaemia in obese Zucker rats relates to oxytocin degradation in liver and adipose tissue. J. Endocrinol. 220, 333-343. doi: 10. 1530/JOE-13-0417

Gao, F., Zheng, K. I., Wang, X. B., Sun, Q. F., Pan, K. H., Wang, T. Y., et al. (2020). Obesity is a risk factor for greater COVID-19 severity. Diabetes Care 43, e72-e74.

George, J. M. (1978). Immunoreactive vasopressin and oxytocin: concentration in individual human hypothalamic nuclei. Science 200, 342-343. doi: 10.1126/ science. 556308

Gimpl, G., and Fahrenholz, F. (2001). The oxytocin receptor system: structure, function, and regulation. Physiol. Rev. 81, 629-683.

Ginsberg, S. D., Hof, P. R., Young, W. G., and Morrison, J. H. (1994). Noradrenergic innervation of vasopressin- and oxytocin-containing neurons in the hypothalamic paraventricular nucleus of the macaque monkey: quantitative analysis using double-label immunohistochemistry and confocal laser microscopy. J. Comp. Neurol. 341, 476-491. doi: 10.1002/cne.90341 0405

Gossen, A., Hahn, A., Westphal, L., Prinz, S., Schultz, R. T., Grunder, G., et al. (2012). Oxytocin plasma concentrations after single intranasal oxytocin administration - a study in healthy men. Neuropeptides 46, 211-215. doi: 10.1016/j.npep.2012.07.001

Gould, B. R., and Zingg, H. H. (2003). Mapping oxytocin receptor gene expression in the mouse brain and mammary gland using an oxytocin receptor-LacZ reporter mouse. Neuroscience 122, 155-167. doi: 10.1016/s0306-4522(03) 00283-5

Gouzenes, L., Desarmenien, M. G., Hussy, N., Richard, P., and Moos, F. C. (1998). Vasopressin regularizes the phasic firing pattern of rat hypothalamic magnocellular vasopressin neurons. J. Neurosci. 18, 1879-1885. doi: 10.1523/ JNEUROSCI.18-05-01879.1998
Greenfield, J. R., Miller, J. W., Keogh, J. M., Henning, E., Satterwhite, J. H., Cameron, G. S., et al. (2009). Modulation of blood pressure by central melanocortinergic pathways. N. Engl. J. Med. 360, 44-52.

Grinevich, V., and Neumann, I. D. (2020). Brain oxytocin: how puzzle stones from animal studies translate into psychiatry. Mol. Psychiatry 26, 265-279. doi: 10.1038/s41380-020-0802-9

Grundy, S. M. (2008). Metabolic syndrome pandemic. Arterioscler. Thromb. Vasc. Biol. 28, 629-636.

Guo, W., Li, M., Dong, Y., Zhou, H., Zhang, Z., Tian, C., et al. (2020). Diabetes is a risk factor for the progression and prognosis of COVID-19. Diabetes Metab. Res. Rev. [Epub ahead of print].

Gutkowska, J., and Jankowski, M. (2012). Oxytocin revisited: its role in cardiovascular regulation. J. Neuroendocrinol. 24, 599-608.

Hales, C. M., Carroll, M. D., Fryar, C. D., and Ogden, C. L. (2020). Prevalence of obesity and severe obesity among adults: United States, 2017-2018. NCHS Data Brief 360, 1-8.

Hallbeck, M., Larhammar, D., and Blomqvist, A. (2001). Neuropeptide expression in rat paraventricular hypothalamic neurons that project to the spinal cord. J. Comp. Neurol. 433, 222-238.

Halseth, K. Shan, Gilder, K., Malone, M., Acevedo, L., and Fujioka, K. (2018). Quality of life, binge eating and sexual function in participants treated for obesity with sustained release naltrexone/bupropion. Obes. Sci. Pract. 4, 141152. doi: $10.1002 / o s p 4.156$

Hayashi, R., Kasahara, Y., Hidema, S., Fukumitsu, S., Nakagawa, K., and Nishimori, K. (2020). Oxytocin ameliorates impaired behaviors of high fat diet-induced obese mice. Front. Endocrinol. 11:379. doi: 10.3389/fendo.2020.0 0379

Head, M. A., Levine, A. S., Christian, D. G., Klockars, A., and Olszewski, P. K. (2021). Effect of combination of peripheral oxytocin and naltrexone at subthreshold doses on food intake, body weight and feeding-related brain gene expression in male rats. Physiol. Behav. 238:113464. doi: 10.1016/j.physbeh. 2021.113464

Herisson, F. M., Waas, J. R., Fredriksson, R., Schioth, H. B., Levine, A. S., and Olszewski, P. K. (2016). Oxytocin acting in the nucleus accumbens core decreases food intake. J. Neuroendocrinol. 28:12381. doi: 10.1111/jne.12381

Hicks, C., Jorgensen, W., Brown, C., Fardell, J., Koehbach, J., Gruber, C. W., et al. (2012). The nonpeptide oxytocin receptor agonist WAY 267,464: receptorbinding profile, prosocial effects and distribution of c-Fos expression in adolescent rats. J. Neuroendocrinol. 24, 1012-1029. doi: 10.1111/j.1365-2826. 2012.02311.x

Hicks, C., Ramos, L., Reekie, T., Misagh, G. H., Narlawar, R., Kassiou, M., et al. (2014). Body temperature and cardiac changes induced by peripherally administered oxytocin, vasopressin and the non-peptide oxytocin receptor agonist WAY 267,464: a biotelemetry study in rats. Br. J. Pharmacol. 171, 2868-2887. doi: 10.1111/bph.12613

Hidema, S., Fukuda, T., Hiraoka, Y., Mizukami, H., Hayashi, R., Otsuka, A., et al. (2016). Generation of Oxtr cDNA(HA) -Ires-Cre mice for gene expression in an oxytocin receptor specific manner. J. Cell. Biochem. 117, 1099-1111. doi: $10.1002 / j \mathrm{jb} .25393$

Ho, J. M., Anekonda, V. T., Thompson, B. W., Zhu, M., Curry, R. W., Hwang, B. H., et al. (2014). Hindbrain oxytocin receptors contribute to the effects of circulating oxytocin on food intake in male rats. Endocrinology 155, 2845-2857. doi: 10.1210/en.2014-1148

Hollander, P., Gupta, A. K., Plodkowski, R., Greenway, F., Bays, H., Burns, C., et al. (2013). Effects of naltrexone sustained-release/bupropion sustained-release combination therapy on body weight and glycemic parameters in overweight and obese patients with type 2 diabetes. Diabetes Care 36, 4022-4029. doi: $10.2337 / \mathrm{dc} 13-0234$

Hsu, E. A., Miller, J. L., Perez, F. A., and Roth, C. L. (2017). Oxytocin and Naltrexone successfully treat hypothalamic obesity in a boy postcraniopharyngioma resection. J. Clin. Endocrinol. Metab. 103, 370-375. doi: $10.1210 /$ jc. $2017-02080$

Insel, T. R., Winslow, J. T., and Witt, D. M. (1992). Homologous regulation of brain oxytocin receptors. Endocrinology 130, 2602-2608.

Iwasa, T., Matsuzaki, T., Mayila, Y., Yanagihara, R., Yamamoto, Y., Kawakita, T., et al. (2019b). Oxytocin treatment reduced food intake and body fat and 
ameliorated obesity in ovariectomized female rats. Neuropeptides $75,49-57$. doi: 10.1016/j.npep.2019.03.002

Iwasa, T., Matsuzaki, T., Mayila, Y., Kawakita, T., Yanagihara, R., and Irahara, M. (2019a). The effects of chronic oxytocin administration on body weight and food intake in DHT-induced PCOS model rats. Gynecol. Endocrinol. 36, 55-60.

Iwasa, T., Matsuzaki, T., Mayila, Y., Kawakita, T., Yanagihara, R., and Irahara, M. (2020). The effects of chronic oxytocin administration on body weight and food intake in DHT-induced PCOS model rats. Gynecol. Endocrinol. 36, 55-60.

Iwasaki, Y., Kumari, P., Wang, L., Hidema, S., Nishimori, K., and Yada, T. (2019). Relay of peripheral oxytocin to central oxytocin neurons via vagal afferents for regulating feeding. Biochem. Biophys. Res. Commun. 519, 553-558. doi: 10.1016/j.bbrc.2019.09.039

Iwasaki, Y., Maejima, Y., Suyama, S., Yoshida, M., Arai, T., Katsurada, K., et al. (2014). Peripheral oxytocin activates vagal afferent neurons to suppress feeding in normal and leptin-resistant mice: a route for ameliorating hyperphagia and obesity. Am. J. Physiol. Regul. Integr. Comp. Physiol. 308, R360-R369. doi: 10.1152/ajpregu.00344.2014

Iwasaki, Y., Maejima, Y., Suyama, S., Yoshida, M., Arai, T., Katsurada, K., et al. (2015). Peripheral oxytocin activates vagal afferent neurons to suppress feeding in normal and leptin-resistant mice: a route for ameliorating hyperphagia and obesity. Am. J. Physiol. Regul. Integr. Comp. Physiol. 308, R360-R369.

Jankowski, M., Hajjar, F., Kawas, S. A., Mukaddam-Daher, S., Hoffman, G., McCann, S. M., et al. (1998). Rat heart: a site of oxytocin production and action. Proc. Natl. Acad. Sci. U.S.A. 95, 14558-14563. doi: 10.1073/pnas.95.24.14558

Jansen, A. S., Wessendorf, M. W., and Loewy, A. D. (1995). Transneuronal labeling of CNS neuropeptide and monoamine neurons after pseudorabies virus injections into the stellate ganglion. Brain Res. 683, 1-24. doi: 10.1016/00068993(95)00276-v

Jirikowski, G. F., Caldwell, J. D., Pedersen, C. A., and Stumpf, W. E. (1988). Estradiol influences oxytocin-immunoreactive brain systems. Neuroscience 25, 237-248. doi: 10.1016/0306-4522(88)90022-x

Johnstone, L. E., Fong, T. M., and Leng, G. (2006). Neuronal activation in the hypothalamus and brainstem during feeding in rats. Cell Metab. 4, 313-321.

Jordan, R. E., Adab, P., and Cheng, K. K. (2020). Covid-19: risk factors for severe disease and death. BMJ 368:m1198.

Kasahara, Y., Sato, K., Takayanagi, Y., Mizukami, H., Ozawa, K., Hidema, S., et al. (2013). Oxytocin receptor in the hypothalamus is sufficient to rescue normal thermoregulatory function in male oxytocin receptor knockout mice. Endocrinology 154, 4305-4315. doi: 10.1210/en.2012-2206

Kasahara, Y., Takayanagi, Y., Kawada, T., Itoi, K., and Nishimori, K. (2007). Impaired thermoregulatory ability of oxytocin-deficient mice during coldexposure. Biosci. Biotechnol. Biochem. 71, 3122-3126. doi: 10.1271/bbb.70498

Kasahara, Y., Tateishi, Y., Hiraoka, Y., Otsuka, A., Mizukami, H., Ozawa, K., et al. (2015). Role of the oxytocin receptor expressed in the rostral medullary raphe in thermoregulation during cold conditions. Front. Endocrinol. 6:180. doi: 10.3389/fendo.2015.00180

Kataoka, N., Hioki, H., Kaneko, T., and Nakamura, K. (2014). Psychological stress activates a dorsomedial hypothalamus-medullary raphe circuit driving brown adipose tissue thermogenesis and hyperthermia. Cell Metab. 20, 346-358. doi: 10.1016/j.cmet.2014.05.018

Kawata, M., and Sano, Y. (1982). Immunohistochemical identification of the oxytocin and vasopressin neurons in the hypothalamus of the monkey (Macaca fuscata). Anatom. Embryol. 165, 151-167. doi: 10.1007/BF00305474

Kendrick, K. M. (2000). Oxytocin, motherhood and bonding. Exp. Physiol. 85, 111S-124S. doi: 10.1111/j.1469-445x.2000.tb00014.x

Kendrick, K. M., Keverne, E. B., Baldwin, B. A., and Sharman, D. F. (1986). Cerebrospinal fluid levels of acetylcholinesterase, monoamines and oxytocin during labour, parturition, vaginocervical stimulation, lamb separation and suckling in sheep. Neuroendocrinology 44, 149-156. doi: 10.1159/000124638

Kievit, P., Halem, H., Marks, D. L., Dong, J. Z., Glavas, M. M., Sinnayah, P., et al. (2013). Chronic treatment with a melanocortin-4 receptor agonist causes weight loss, reduces insulin resistance, and improves cardiovascular function in diet-induced obese rhesus macaques. Diabetes 62, 490-497. doi: 10.2337/db120598

Kirchgessner, A. L., and Sclafani, A. (1988). PVN-hindbrain pathway involved in the hypothalamic hyperphagia-obesity syndrome. Physiol. Behav. 42, 517-528.
Kirchgessner, A. L., Sclafani, A., and Nilaver, G. (1988). Histochemical identification of a PVN-hindbrain feeding pathway. Physiol. Behav. 42, 529-543. doi: 10.1016/0031-9384(88)90154-0

Kirkpatrick, M. G., Francis, S. M., Lee, R., de Wit, H., and Jacob, S. (2014). Plasma oxytocin concentrations following MDMA or intranasal oxytocin in humans. Psychoneuroendocrinology 46, 23-31.

Klockars, A., Brunton, C., Li, L., Levine, A. S., and Olszewski, P. K. (2017). Intravenous administration of oxytocin in rats acutely decreases deprivationinduced chow intake, but it fails to affect consumption of palatable solutions. Peptides 93, 13-19. doi: 10.1016/j.peptides.2017.04.010

Klockars, A., Levine, A. S., and Olszewski, P. K. (2015). Central oxytocin and food intake: focus on macronutrient-driven reward. Front. Endocrinol. 6:65. doi: 10.3389/fendo.2015.00065

Klockars, O. A., Klockars, A., Levine, A. S., and Olszewski, P. K. (2018). Oxytocin administration in the basolateral and central nuclei of amygdala moderately suppresses food intake. Neuroreport 29, 504-510. doi: 10.1097/ WNR.0000000000001005

Klockars, O. A., Waas, J. R., Klockars, A., Levine, A. S., and Olszewski, P. K. (2017). Neural basis of ventromedial hypothalamic oxytocin-driven decrease in appetite. Neuroscience 366, 54-61. doi: 10.1016/j.neuroscience.2017.10.008

Knobloch, H. S., Charlet, A., Hoffmann, L. C., Eliava, M., Khrulev, S., Cetin, A. H., et al. (2012). Evoked axonal oxytocin release in the central amygdala attenuates fear response. Neuron 73, 553-566. doi: 10.1016/j.neuron.2011.11.030

Koutcherov, Y., Mai, J. K., Ashwell, K. W., and Paxinos, G. (2000). Organization of the human paraventricular hypothalamic nucleus. J. Comp. Neurol. 423, 299-318.

Kublaoui, B. M., Gemelli, T., Tolson, K. P., Wang, Y., and Zinn, A. R. (2008). Oxytocin deficiency mediates hyperphagic obesity of Sim1 haploinsufficient mice. Mol. Endocrinol. 22, 1723-1734. doi: 10.1210/me.2008-0067

Kusminski, C. M., Bickel, P. E., and Scherer, P. E. (2016). Targeting adipose tissue in the treatment of obesity-associated diabetes. Nat. Rev. Drug Discov. 15, 639-660.

Labyb, M., Chretien, C., Caillon, A., Rohner-Jeanrenaud, F., and Altirriba, J. (2018). Oxytocin administration alleviates acute but not chronic leptin resistance of diet-induced obese mice. Int. J. Mol. Sci. 20:88.

Lawson, E. A. (2017). The effects of oxytocin on eating behaviour and metabolism in humans. Nat. Rev. Endocrinol. 13, 700-709.

Lawson, E. A., Marengi, D. A., DeSanti, R. L., Holmes, T. M., Schoenfeld, D. A., and Tolley, C. J. (2015). Oxytocin reduces caloric intake in men. Obesity 23, 950-956.

Lawson, E. A., Olszewski, P. K., Weller, A., and Blevins, J. E. (2020). The role of oxytocin in regulation of appetitive behaviour, body weight and glucose homeostasis. J. Neuroendocrinol. 32:e12805. doi: 10.1111/jne.1 2805

Lee, E. S., Uhm, K. O., Lee, Y. M., Kwon, J., Park, S. H., and Soo, K. H. (2008). Oxytocin stimulates glucose uptake in skeletal muscle cells through the calcium-CaMKK-AMPK pathway. Regul. Pept. 151, 71-74. doi: 10.1016/ j.regpep.2008.05.001

Lee, M. R., Scheidweiler, K. B., Diao, X. X., Akhlaghi, F., Cummins, A., Huestis, M. A., et al. (2018). Oxytocin by intranasal and intravenous routes reaches the cerebrospinal fluid in rhesus macaques: determination using a novel oxytocin assay. Mol. Psychiatry 23, 115-122. doi: 10.1038/mp.2017.27

Lein, E. S., Hawrylycz, M. J., Ao, N., Ayres, M., Bensinger, A., Bernard, A., et al. (2007). Genome-wide atlas of gene expression in the adult mouse brain. Nature $445,168-176$.

Leitner, C., and Bartness, T. J. (2009). Acute brown adipose tissue temperature response to cold in monosodium glutamate-treated Siberian hamsters. Brain Res. 1292, 38-51. doi: 10.1016/j.brainres.2009.07.062

Leng, G., and Ludwig, M. (2008). Neurotransmitters and peptides: whispered secrets and public announcements. J. Physiol. 586, 5625-5632. doi: 10.1113/ jphysiol.2008.159103

Leng, G., and Ludwig, M. (2016a). Intranasal oxytocin: myths and delusions. Biol. Psychiatry 79, 243-250. doi: 10.1016/j.biopsych.2015. 05.003

Leng, G., and Ludwig, M. (2016b). Reply to: improving research standards to restore trust in intranasal oxytocin. Biol. Psychiatry 79, e55-e56. doi: 10.1016/j. biopsych.2015.08.030 
Leng, G., and Ludwig, M. (2016c). Reply to: intranasal oxytocin mechanisms can be better understood, but its effects on social cognition and behavior are not to be sniffed at. Biol. Psychiatry 79, e51-e52. doi: 10.1016/j.biopsych.2015.06.022

Leng, G., Onaka, T., Caquineau, C., Sabatier, N., Tobin, V. A., and Takayanagi, Y. (2008). Oxytocin and appetite. Prog. Brain Res. 170, 137-151.

Leng, G., and Sabatier, N. (2017). Oxytocin - the sweet hormone? Trends Endocrinol. Metab. TEM 28, 365-376.

Li, L., Kong, X., Liu, H., and Liu, C. (2007). Systemic oxytocin and vasopressin excite gastrointestinal motility through oxytocin receptor in rabbits. Neurogastroenterol. Motil. 19, 839-844. doi: 10.1111/j.1365-2982.2007.00953.x

Liao, P. Y., Chiu, Y. M., Yu, J. H., and Chen, S. K. (2020). Mapping central projection of oxytocin neurons in unmated mice using cre and alkaline phosphatase reporter. Front. Neuroanat. 14:559402. doi: 10.3389/fnana.2020. 559402

Liu, C. M., Hsu, T. M., Suarez, A. N., Subramanian, K. S., Fatemi, R. A., Cortella, A. M., et al. (2020b). Central oxytocin signaling inhibits food reward-motivated behaviors and VTA dopamine responses to food-predictive cues in male rats. Hormon. Behav. 126:104855. doi: 10.1016/j.yhbeh.2020.104855

Liu, C. M., Davis, E. A., Suarez, A. N., Wood, R. I., Noble, E. E., and Kanoski, S. E. (2020a). Sex differences and estrous influences on oxytocin control of food intake. Neuroscience 447, 63-73.

Lokrantz, C. M., vnas-Moberg, K. U., and Kaplan, J. M. (1997). Effects of central oxytocin administration on intraoral intake of glucose in deprived and nondeprived rats. Physiol. Behav. 62, 347-352. doi: 10.1016/s0031-9384(97) 00021-8

Loup, F., Tribollet, E., Dubois-Dauphin, M., and Dreifuss, J. J. (1991). Localization of high-affinity binding sites for oxytocin and vasopressin in the human brain. An autoradiographic study. Brain Res. 555, 220-232. doi: 10.1016/00068993(91)90345-v

Loup, F., Tribollet, E., Dubois-Dauphin, M., Pizzolato, G., and Dreifuss, J. J. (1989). Localization of oxytocin binding sites in the human brainstem and upper spinal cord: an autoradiographic study. Brain Res. 500, 223-230.

Ludwig, M., and Leng, G. (2006). Dendritic peptide release and peptidedependent behaviours. Nat. Rev. Neurosci. 7, 126-136. doi: 10.1038/nrn 1845

Ludwig, M., Tobin, V. A., Callahan, M. F., Papadaki, E., Becker, A., Engelmann, M., et al. (2013). Intranasal application of vasopressin fails to elicit changes in brain immediate early gene expression, neural activity and behavioural performance of rats. J. Neuroendocrinol. 25, 655-667. doi: 10.1111/jne.12046

Luo, F., Mu, Y., Gao, C., Xiao, Y., Zhou, Q., Yang, Y., et al. (2019). Whole-brain patterns of the presynaptic inputs and axonal projections of BDNF neurons in the paraventricular nucleus. J. Genet. Genom. 46, 31-40. doi: 10.1016/j.jgg.2018. 11.004

MacDonald, E., Dadds, M. R., Brennan, J. L., Williams, K., Levy, F., and Cauchi, A. J. (2011). A review of safety, side-effects and subjective reactions to intranasal oxytocin in human research. Psychoneuroendocrinology 36, 1114-1126. doi: 10.1016/j.psyneuen.2011.02.015

Maejima, Y., Aoyama, M., Sakamoto, K., Jojima, T., Aso, Y., Takasu, K., et al. (2017). Impact of sex, fat distribution and initial body weight on oxytocin's body weight regulation. Sci. Rep. 7:8599. doi: 10.1038/s41598-017-09318-7

Maejima, Y., Horita, S., Otsuka, A., Hidema, S., Nishimori, K., and Shimomura, K. (2020). Oral oxytocin delivery with proton pump inhibitor pretreatment decreases food intake. Peptides 128:170312. doi: 10.1016/j.peptides.2020. 170312

Maejima, Y., Iwasaki, Y., Yamahara, Y., Kodaira, M., Sedbazar, U., and Yada, T. (2011). Peripheral oxytocin treatment ameliorates obesity by reducing food intake and visceral fat mass. Aging 3, 1169-1177. doi: 10.18632/aging.100408

Maejima, Y., Kato, S., Horita, S., Ueta, Y., Takenoshita, S., Kobayashi, K., et al. (2019). The hypothalamus to brainstem circuit suppresses late-onset body weight gain. Sci. Rep. 9:18360. doi: 10.1038/s41598-019-54870-z

Maejima, Y., Rita, R. S., Santoso, P., Aoyama, M., Hiraoka, Y., Nishimori, K., et al. (2015). Nasal oxytocin administration reduces food intake without affecting locomotor activity and glycemia with c-fos induction in limited brain areas. Neuroendocrinology 101, 35-44. doi: 10.1159/000371636

Maejima, Y., Sakuma, K., Santoso, P., Gantulga, D., Katsurada, K., Ueta, Y., et al. (2014). Oxytocinergic circuit from paraventricular and supraoptic nuclei to arcuate POMC neurons in hypothalamus. FEBS Lett. 588, 4404-4412. doi: 10.1016/j.febslet.2014.10.010
Maejima, Y., Sedbazar, U., Suyama, S., Kohno, D., Onaka, T., Takano, E., et al. (2009). Nesfatin-1-regulated oxytocinergic signaling in the paraventricular nucleus causes anorexia through a leptin-independent melanocortin pathway. Cell Metab. 10, 355-365. doi: 10.1016/j.cmet.2009.09.002

Matarazzo, V., Schaller, F., Nedelec, E., Benani, A., Penicaud, L., Muscatelli, F., et al. (2012). Inactivation of Socs3 in the hypothalamus enhances the hindbrain response to endogenous satiety signals via oxytocin signaling. J. Neurosci. 32, 17097-17107. doi: 10.1523/JNEUROSCI.1669-12.2012

McCann, M. J., Verbalis, J. G., and Stricker, E. M. (1989). LiCl and CCK inhibit gastric emptying and feeding and stimulate OT secretion in rats. Am. J. Physiol. 256, R463-R468. doi: 10.1152/ajpregu.1989.256.2.R463

McCormack, S. E., Blevins, J. E., and Lawson, E. A. (2020). Metabolic effects of oxytocin. Endocrine Rev. 41, 121-145.

Mens, W. B., Witter, A., and van Wimersma Greidanus, T. B. (1983). Penetration of neurohypophyseal hormones from plasma into cerebrospinal fluid (CSF): half-times of disappearance of these neuropeptides from CSF. Brain Res. 262, 143-149. doi: 10.1016/0006-8993(83)90478-x

Meredith, M. E., Salameh, T. S., and Banks, W. A. (2015). Intranasal delivery of proteins and peptides in the treatment of neurodegenerative diseases. AAPS J. $17,780-787$.

Michalakis, K., and Ilias, I. (2020). SARS-CoV-2 infection and obesity: common inflammatory and metabolic aspects. Diabetes Metab. Syndr. 14, 469-471.

Miller, G. (2013). The promise and perils of oxytocin. Science 339, 267-269. doi: 10.1126/science.339.6117.267

Modi, M. E., Connor-Stroud, F., Landgraf, R., Young, L. J., and Parr, L. A. (2014). Aerosolized oxytocin increases cerebrospinal fluid oxytocin in rhesus macaques. Psychoneuroendocrinology 45, 49-57. doi: 10.1016/j.psyneuen.2014. 02.011

Monstein, H. J., Grahn, N., Truedsson, M., and Ohlsson, B. (2004). Oxytocin and oxytocin-receptor mRNA expression in the human gastrointestinal tract: a polymerase chain reaction study. Regul. Pept. 119, 39-44.

Montag, C., Brockmann, E. M., Bayerl, M., Rujescu, D., Muller, D. J., and Gallinat, J. (2012). Oxytocin and oxytocin receptor gene polymorphisms and risk for schizophrenia: a case-control study. World J. Biol. Psychiatry 14, 500-508.

Monte, O. Dal, Noble, P. L., Turchi, J., Cummins, A., and Averbeck, B. B. (2014). CSF and blood oxytocin concentration changes following intranasal delivery in macaque. PLoS one 9:e103677. doi: 10.1371/journal.pone.0103677

Moos, F., and Richard, P. (1989). Paraventricular and supraoptic bursting oxytocin cells in rat are locally regulated by oxytocin and functionally related. J. Physiol. 408, 1-18. doi: 10.1113/jphysiol.1989.sp017442

Morrison, S. F., Madden, C. J., and Tupone, D. (2014). Central neural regulation of brown adipose tissue thermogenesis and energy expenditure. Cell Metab. 19, 741-756.

Morton, G. J., Thatcher, B. S., Reidelberger, R. D., Ogimoto, K., Wolden-Hanson, T., Baskin, D. G., et al. (2012). Peripheral oxytocin suppresses food intake and causes weight loss in diet-induced obese rats. Am. J. Physiol. Endoc. M. 302, E134-E144. doi: 10.1152/ajpendo.00296.2011

Muchmore, D. B., Little, S. A., de Haen, C., and dual, A. (1981). mechanism of action of ocytocin in rat epididymal fat cells. J. Biol. Chem. 256, 365-372.

Mullis, K., Kay, K., and Williams, D. L. (2013). Oxytocin action in the ventral tegmental area affects sucrose intake. Brain Res. 1513, 85-91. doi: 10.1016/j. brainres.2013.03.026

Nasanbuyan, N., Yoshida, M., Takayanagi, Y., Inutsuka, A., Nishimori, K., Yamanaka, A., et al. (2018). Oxytocin-oxytocin receptor systems facilitate social defeat posture in male mice. Endocrinology 159, 763-775. doi: 10.1210/en.201700606

Nation, D. A., Szeto, A., Mendez, A. J., Brooks, L. G., Zaias, J., Herderick, E. E., et al. (2010). Oxytocin attenuates atherosclerosis and adipose tissue inflammation in socially isolated ApoE-/- mice. Psychos. Med. 72, 376-382. doi: 10.1097/PSY. 0b013e3181d74c48

Nedergaard, J., and Cannon, B. (2014). The browning of white adipose tissue: some burning issues. Cell Metab. 20, 396-407.

Neumann, I. D., Maloumby, R., Beiderbeck, D. I., Lukas, M., and Landgraf, R. (2013). Increased brain and plasma oxytocin after nasal and peripheral administration in rats and mice. Psychoneuroendocrinology 38, 1985-1993. doi: 10.1016/j.psyneuen.2013.03.003 
Nguyen, N. T., Magno, C. P., Lane, K. T., Hinojosa, M. W., and Lane, J. S. (2008). Association of hypertension, diabetes, dyslipidemia, and metabolic syndrome with obesity: findings from the National Health and Nutrition Examination Survey, 1999 to 2004. J. Am. College Surg. 207, 928-934.

Noble, E. E., Billington, C. J., Kotz, C. M., and Wang, C. (2014). Oxytocin in the ventromedial hypothalamic nucleus reduces feeding and acutely increases energy expenditure. Am. J. Physiol. Regul. Integr. Comp. Physiol. 307, R737R745. doi: 10.1152/ajpregu.00118.2014

Nunn, N., Womack, M., Dart, C., and Barrett-Jolley, R. (2011). Function and pharmacology of spinally-projecting sympathetic pre-autonomic neurones in the paraventricular nucleus of the hypothalamus. Curr. Neuropharmacol. 9, 262-277. doi: 10.2174/157015911795596531

Ogden, C. L., Carroll, M. D., Kit, B. K., and Flegal, K. M. (2012). Prevalence of obesity in the United States, 2009-2010. NCHS Data Brief 82, 1-8.

Ohlsson, B., Truedsson, M., Djerf, P., and Sundler, F. (2006). Oxytocin is expressed throughout the human gastrointestinal tract. Regul. Pept. 135, 7-11.

Oldfield, B. J., Giles, M. E., Watson, A., Anderson, C., Colvill, L. M., and McKinley, M. J. (2002). The neurochemical characterisation of hypothalamic pathways projecting polysynaptically to brown adipose tissue in the rat. Neuroscience 110 , 515-526. doi: 10.1016/s0306-4522(01)00555-3

Olson, B. R., Drutarosky, M. D., Stricker, E. M., and Verbalis, J. G. (1991b). Brain oxytocin receptor antagonism blunts the effects of anorexigenic treatments in rats: evidence for central oxytocin inhibition of food intake. Endocrinology 129, 785-791. doi: 10.1210/endo-129-2-785

Olson, B. R., Drutarosky, M. D., Chow, M. S., Hruby, V. J., Stricker, E. M., and Verbalis, J. G. (1991a). Oxytocin and an oxytocin agonist administered centrally decrease food intake in rats. Peptides 1991, 113-118. doi: 10.1016/ 0196-9781(91)90176-p

Olson, B. R., Hoffman, G. E., Sved, A. F., Stricker, E. M., and Verbalis, J. G. (1992). Cholecystokinin induces $\mathrm{c}$-fos expression in hypothalamic oxytocinergic neurons projecting to the dorsal vagal complex. Brain Res. 569, 238-248. doi: 10.1016/0006-8993(92)90635-m

Olszewski, P. K., Klockars, A., Olszewska, A. M., Fredriksson, R., Schioth, H. B., and Levine, A. S. (2010). Molecular, immunohistochemical, and pharmacological evidence of oxytocin's role as inhibitor of carbohydrate but not fat intake. Endocrinology 151, 4736-4744. doi: 10.1210/en.2010-0151

Olszewski, P. K., Wirth, M. M., Shaw, T. J., Grace, M. K., Billington, C. J., Giraudo, S. Q., et al. (2001). Role of alpha-MSH in the regulation of consummatory behavior: immunohistochemical evidence. Am. J. Physiol. Regul. Integr. Comp. Physiol. 281, R673-R680. doi: 10.1152/ajpregu.2001.281.2.R673

Ong, Z. Y., Alhadeff, A. L., and Grill, H. J. (2015). Medial nucleus tractus solitarius oxytocin receptor signaling and food intake control: the role of gastrointestinal satiation signal processing. Am. J. Physiol. Regul. Integr. Comp. Physiol. 308, R800-R806. doi: 10.1152/ajpregu.00534.2014

Ong, Z. Y., Bongiorno, D. M., Hernando, M. A., and Grill, H. J. (2017). Effects of endogenous oxytocin receptor signaling in nucleus tractus solitarius on satiation-mediated feeding and thermogenic control in male rats. Endocrinology 158, 2826-2836. doi: 10.1210/en.2017-00200

Ott, V., Finlayson, G., Lehnert, H., Heitmann, B., Heinrichs, M., Born, J., et al. (2013). Oxytocin reduces reward-driven food intake in humans. Diabetes 62, 3418-3425.

Paiva, L., Lozic, M., Allchorne, A., Grinevich, V., and Ludwig, M. (2021). Identification of peripheral oxytocin-expressing cells using systemically applied cell-type specific adeno-associated viral vector. J. Neuroendocrinol. 33:e12970. doi: 10.1111/jne.12970

Paulin, C., Dubois, P. M., Czernichow, P., and Dubois, M. P. (1978). Immunocytological evidence for oxytocin neurons in the human fetal hypothalamus. Cell Tissue Res. 188, 259-264. doi: 10.1007/BF00222635

Peris, J., MacFadyen, K., Smith, J. A., de Kloet, A. D., Wang, L., and Krause, E. G. (2016). Oxytocin receptors are expressed on dopamine and glutamate neurons in the mouse ventral tegmental area that project to nucleus accumbens and other mesolimbic targets. J. Comp. Neurol. 525, 1094-1108. doi: 10.1002/cne. 24116

Peris, J., MacFadyen, K., Smith, J. A., de Kloet, A. D., Wang, L., and Krause, E. G. (2017). Oxytocin receptors are expressed on dopamine and glutamate neurons in the mouse ventral tegmental area that project to nucleus accumbens and other mesolimbic targets. J. Comp. Neurol. 525, 1094-1108.
Peters, S., Slattery, D. A., Uschold-Schmidt, N., Reber, S. O., and Neumann, I. D. (2014). Dose-dependent effects of chronic central infusion of oxytocin on anxiety, oxytocin receptor binding and stress-related parameters in mice. Psychoneuroendocrinology 42, 225-236. doi: 10.1016/j.psyneuen.2014. 01.021

Petersson, M. (2002). Cardiovascular effects of oxytocin. Prog. Brain Res. 139, 281-288.

Petersson, M., Alster, P., Lundeberg, T., and vnas-Moberg, K. U. (1996). Oxytocin causes a long-term decrease of blood pressure in female and male rats. Physiol. Behav. 60, 1311-1315.

Pinder, A. J., Dresner, M., Calow, C., Shorten, G. D., O’Riordan, J., and Johnson, R. (2002). Haemodynamic changes caused by oxytocin during caesarean section under spinal anaesthesia. Int. J. Obstet. Anesth. 11, 156-159.

Plante, E., Menaouar, A., Danalache, B. A., Yip, D., Broderick, T. L., Chiasson, J. L., et al. (2015). Oxytocin treatment prevents the cardiomyopathy observed in obese diabetic male db/db mice. Endocrinology 156, 1416-1428. doi: 10.1210/ en.2014-1718

Plessow, F., Marengi, D. A., Perry, S. K., Felicione, J. M., Franklin, R., Holmes, T. M., et al. (2018). Effects of intranasal oxytocin on the blood oxygenation level-dependent signal in food motivation and cognitive control pathways in overweight and obese men. Neuropsychopharmacology 43, 638-645. doi: 10. 1038/npp.2017.226

Pow, D. V., and Morris, J. F. (1989). Dendrites of hypothalamic magnocellular neurons release neurohypophysial peptides by exocytosis. Neuroscience 32, 435-439.

Qin, J., Feng, M., Wang, C., Ye, Y., Wang, P. S., and Liu, C. (2009). Oxytocin receptor expressed on the smooth muscle mediates the excitatory effect of oxytocin on gastric motility in rats. Neurogastroenterol. Motil. 21, 430-438. doi: 10.1111/j.1365-2982.2009.01282.x

Ragen, B. J., and Bales, K. L. (2013). "Oxytocin and vasopressin in non-human primates," in Oxytocin, Vasopressin and Related Peptides in the Regulation of Behavior, eds E. Choleris, D. W. Pfaff, and M. Kavaliers (Cambridge: Cambridge University Press), 288-306.

Rajagopal, S., and Cheskin, L. J. (2021). In overweight or obese adults without diabetes, semaglutide increased weight loss and GI disorders. Ann. Intern. Med. 174:JC80.

Rault, J. L., Carter, C. S., Garner, J. P., Marchant-Forde, J. N., Richert, B. T., and Lay, D. C. Jr. (2013). Repeated intranasal oxytocin administration in early life dysregulates the HPA axis and alters social behavior. Physiol. Behav. 112-113, 40-48. doi: 10.1016/j.physbeh.2013.02.007

Reiter, M. K., Kremarik, P., Freund-Mercier, M. J., Stoeckel, M. E., Desaulles, E., and Feltz, P. (1994). Localization of oxytocin binding sites in the thoracic and upper lumbar spinal cord of the adult and postnatal rat: a histoautoradiographic study. Eur. J. Neurosci. 6, 98-104. doi: 10.1111/j.1460-9568.1994.tb00251.x

Renaud, L. P., and Bourque, C. W. (1991). Neurophysiology and neuropharmacology of hypothalamic magnocellular neurons secreting vasopressin and oxytocin. Prog. Neurobiol. 36, 131-169. doi: 10.1016/03010082(91)90020-2

Rinaman, L. (1998). Oxytocinergic inputs to the nucleus of the solitary tract and dorsal motor nucleus of the vagus in neonatal rats. J. Comp. Neurol. 399, 101109. doi: 10.1002/(sici)1096-9861(19980914)399:1\&lt;101::aid-cne8\&gt;3.0.co; $2-5$

Rinaman, L., and Rothe, E. E. (2002). GLP-1 receptor signaling contributes to anorexigenic effect of centrally administered oxytocin in rats. Am. J. Physiol. Regul. Integr. Comp. Physiol. 283, R99-R106. doi: 10.1152/ajpregu.00008.2002

Ring, R. H., Malberg, J. E., Potestio, L., Ping, J., Boikess, S., Luo, B., et al. (2006). Anxiolytic-like activity of oxytocin in male mice: behavioral and autonomic evidence, therapeutic implications. Psychopharmacology 185, 218-225. doi: 10.1007/s00213-005-0293-Z

Ring, R. H., Schechter, L. E., Leonard, S. K., Dwyer, J. M., Platt, B. J., Graf, R., et al. (2010). Receptor and behavioral pharmacology of WAY-267464, a non-peptide oxytocin receptor agonist. Neuropharmacology 58, 69-77.

Roberts, Z. S., Wolden-Hanson, T. H., Matsen, M. E., Ryu, V., Vaughan, C. H., Graham, J. L., et al. (2017). Chronic hindbrain administration of oxytocin is sufficient to elicit weight loss in diet-induced obese rats. Am. J. Physiol. Regul. Integr. Comp. Physiol. 313, R357-R371. doi: 10.1152/ajpregu.00169.2017

Rodgers, R. J., Tschop, M. H., and Wilding, J. P. (2012). Anti-obesity drugs: past, present and future. Dis. Models Mech. 5, 621-626. 
Rogers, R. C., and Hermann, G. E. (1987). Oxytocin, oxytocin antagonist, TRH, and hypothalamic paraventricular nucleus stimulation effects on gastric motility. Peptides 8, 505-513. doi: 10.1016/0196-9781(87)90017-9

Romero-Fernandez, W., Borroto-Escuela, D. O., Agnati, L. F., and Fuxe, K. (2013). Evidence for the existence of dopamine D2-oxytocin receptor heteromers in the ventral and dorsal striatum with facilitatory receptor-receptor interactions. Mol. Psychiatry 18, 849-850. doi: 10.1038/mp.2012.103

Rosen, G. J., de Vries, G. J., Goldman, S. L., Goldman, B. D., and Forger, N. G. (2008). Distribution of oxytocin in the brain of a eusocial rodent. Neuroscience $155,809-817$.

Rosenbaum, M., Goldsmith, R., Bloomfield, D., Magnano, A., Weimer, L., Heymsfield, S., et al. (2005). Low-dose leptin reverses skeletal muscle, autonomic, and neuroendocrine adaptations to maintenance of reduced weight. J. Clin. Investig. 115, 3579-3586. doi: 10.1172/JCI25977

Rosenbaum, M., Kissileff, H. R., Mayer, L. E., Hirsch, J., and Leibel, R. L. (2010). Energy intake in weight-reduced humans. Brain Res. 1350, 95-102.

Rosenbaum, M., Murphy, E. M., Heymsfield, S. B., Matthews, D. E., and Leibel, R. L. (2002). Low dose leptin administration reverses effects of sustained weightreduction on energy expenditure and circulating concentrations of thyroid hormones. J. Clin. Endocrinol. Metab. 87, 2391-2394. doi: 10.1210/jcem.87.5. 8628

Ross, H. E., Cole, C. D., Smith, Y., Neumann, I. D., Landgraf, R., Murphy, A. Z., et al. (2009). Characterization of the oxytocin system regulating affiliative behavior in female prairie voles. Neuroscience 162, 892-903.

Ryan, P. J., Ross, S. I., Campos, C. A., Derkach, V. A., and Palmiter, R. D. (2017). Oxytocin-receptor-expressing neurons in the parabrachial nucleus regulate fluid intake. Nat. Neurosci. 20, 1722-1733. doi: 10.1038/s41593-0170014-z

Sabatier, N., Leng, G., and Menzies, J. (2013). Oxytocin, feeding, and satiety. Front. Endocrinol. 4:35. doi: 10.3389/fendo.2013.00035

Sabatier, N., Rowe, I., and Leng, G. (2007). Central release of oxytocin and the ventromedial hypothalamus. Biochem. Soc. Trans. 35, 1247-1251.

Sawchenko, P. E., and Swanson, L. W. (1982). Immunohistochemical identification of neurons in the paraventricular nucleus of the hypothalamus that project to the medulla or to the spinal cord in the rat. J. Comp. Neurol. 205, 260-272.

Sawchenko, P. E., Swanson, L. W., and Vale, W. W. (1984). Corticotropin-releasing factor: co-expression within distinct subsets of oxytocin-, vasopressin-, and neurotensin-immunoreactive neurons in the hypothalamus of the male rat. J. Neurosci. 4, 1118-1129. doi: 10.1523/JNEUROSCI.04-04-01118.1984

Schaffler, N. Binart, Scholmerich, J., and Buchler, C. (2005). Hypothesis paper Brain talks with fat-evidence for a hypothalamic-pituitary-adipose axis? Neuropeptides 39, 363-367. doi: 10.1016/j.npep.2005.06.003

Schellekens, H., Dinan, T. G., and Cryan, J. F. (2013). Taking two to tango: a role for ghrelin receptor heterodimerization in stress and reward. Front. Neurosci. 7:148. doi: 10.3389/fnins.2013.00148

Schorr, M., Marengi, D. A., Pulumo, R. L., Yu, E., Eddy, K. T., Klibanski, A., et al. (2017). Oxytocin and its relationship to body composition, bone mineral density, and hip geometry across the weight spectrum. J. Clin. Endocrinol. Metab. 102, 2814-2824. doi: 10.1210/jc.2016-3963

Schorscher-Petcu, A., Dupre, A., and Tribollet, E. (2009). Distribution of vasopressin and oxytocin binding sites in the brain and upper spinal cord of the common marmoset. Neurosci. Lett. 461, 217-222. doi: 10.1016/j.neulet.2009. 06.016

Schumacher, M., Coirini, H., Frankfurt, M., and McEwen, B. S. (1989). Localized actions of progesterone in hypothalamus involve oxytocin. Proc. Natl. Acad. Sci. U.S.A. 86, 6798-6801. doi: 10.1073/pnas.86.17.6798

Schwartz, A., and Doucet, E. (2010). Relative changes in resting energy expenditure during weight loss: a systematic review. Obes. Rev. 11, 531-547. doi: 10.1111/j. 1467-789X.2009.00654.x

Schwartz, M. W., Woods, S. C., Porte, D. Jr., Seeley, R. J., and Baskin, D. G. (2000). Central nervous system control of food intake. Nature 404, 661-671.

Seeley, R. J., Yagaloff, K. A., Fisher, S. L., Burn, P., Thiele, T. E., van Dijk, G., et al. (1997). Melanocortin receptors in leptin effects. Nature 390:349.

Seelke, A. M., Rhine, M. A., Khun, K., Shweyk, A. N., Scott, A. M., Bond, J. M., et al. (2018). Intranasal oxytocin reduces weight gain in diet-induced obese prairie voles. Physiol. Behav. 196, 67-77. doi: 10.1016/j.physbeh.2018.08.007
Shahrokh, D. K., Zhang, T. Y., Diorio, J., Gratton, A., and Meaney, M. J. (2010). Oxytocin-dopamine interactions mediate variations in maternal behavior in the rat. Endocrinology 151, 2276-2286. doi: 10.1210/en.2009-1271

Shi, H., and Bartness, T. J. (2001). Neurochemical phenotype of sympathetic nervous system outflow from brain to white fat. Brain Res. Bull. 54, 375-385. doi: 10.1016/s0361-9230(00)00455-x

Smith, A. S., Korgan, A. C., and Young, W. S. (2019). Oxytocin delivered nasally or intraperitoneally reaches the brain and plasma of normal and oxytocin knockout mice. Pharmacol. Res. 146:104324.

Smyth, S., and Heron, A. (2006). Diabetes and obesity: the twin epidemics. Nat. Med. 12, 75-80.

Snider, B., Geiser, A., Yu, X. P., Beebe, E. C., Willency, J. A., Qing, K., et al. (2019). Long-acting and selective oxytocin peptide analogs show antidiabetic and antiobesity effects in male mice. J. Endocrine Soc. 3, 1423-1444. doi: 10.1210/js.2019-00004

Sofroniew, M. V. (1983). Morphology of vasopressin and oxytocin neurones and their central and vascular projections. Prog. Brain Res. 60, 101-114.

Sofroniew, M. V., Weindl, A., Schrell, U., and Wetzstein, R. (1981). Immunohistochemistry of vasopressin, oxytocin and neurophysin in the hypothalamus and extrahypothalamic regions of the human and primate brain. Acta Histochem. Suppl. 24, 79-95.

Song, C. K., Vaughan, C. H., Keen-Rhinehart, E., Harris, R. B., Richard, D., and Bartness, T. J. (2008). Melanocortin-4 receptor mRNA expressed in sympathetic outflow neurons to brown adipose tissue: neuroanatomical and functional evidence. Am. J. Physiol. Regul. Integr. Comp. Physiol. 295, R417-R428. doi: 10.1152/ajpregu.00174.2008

Stanley, S., Pinto, S., Segal, J., Perez, C. A., Viale, A., DeFalco, J., et al. (2010). Identification of neuronal subpopulations that project from hypothalamus to both liver and adipose tissue polysynaptically. Proc. Natl. Acad. Sci. U.S.A. 107, 7024-7029. doi: 10.1073/pnas.1002790107

Striepens, N., Kendrick, K. M., Hanking, V., Landgraf, R., Wullner, U., Maier, W., et al. (2013). Elevated cerebrospinal fluid and blood concentrations of oxytocin following its intranasal administration in humans. Sci. Rep. 3:3440.

Striepens, N., Kendrick, K. M., Maier, W., and Hurlemann, R. (2011). Prosocial effects of oxytocin and clinical evidence for its therapeutic potential. Front. Neuroendocrinol. 32, 426-450. doi: 10.1016/j.yfrne.2011. 07.001

Striepens, N., Schroter, F., Stoffel-Wagner, B., Maier, W., Hurlemann, R., and Scheele, D. (2016). Oxytocin enhances cognitive control of food craving in women. Hum. Brain Mapp. 37, 4276-4285. doi: 10.1002/hbm.23308

Sukhov, R. R., Walker, L. C., Rance, N. E., Price, D. L., and Young, W. S. III (1993). Vasopressin and oxytocin gene expression in the human hypothalamus. J. Comp. Neurol. 337, 295-306.

Sun, L., Lizneva, D., Ji, Y., Colaianni, G., Hadelia, E., Gumerova, A., et al. (2019). Oxytocin regulates body composition. Proc. Natl. Acad. Sci. U.S.A. 116, 26808-26815.

Sutton, A. K., Pei, H., Burnett, K. H., Myers, M. G. Jr., Rhodes, C. J., and Olson, D. P. (2014). Control of food intake and energy expenditure by Nos1 neurons of the paraventricular hypothalamus. J. Neurosci. 34, 15306-15318.

Swaab, D. F., Nijveldt, F., and Pool, C. W. (1975a). Distribution of oxytocin and vasopressin in the rat supraoptic and paraventricular nucleus. J. Endocrinol. 67, 461-462.

Swaab, D. F., Pool, C. W., and Nijveldt, F. (1975b). Immunofluorescence of vasopressin and oxytocin in the rat hypothalamo-neurohypophypopseal system. J. Neural Transm. 36, 195-215. doi: 10.1007/BF0125 3126

Szabo, R., Menesi, R., Szalai, Z., Daruka, L., Toth, G., Gardi, J., et al. (2019). New metabolic influencer on oxytocin release: the ghrelin. Molecules 24:735. doi: $10.3390 /$ molecules 24040735

Tachibana, M., Kagitani-Shimono, K., Mohri, I., Yamamoto, T., Sanefuji, W., Nakamura, A., et al. (2013). Long-term administration of intranasal oxytocin is a safe and promising therapy for early adolescent boys with autism spectrum disorders. J. Child Adolesc. Psychopharmacol. 23, 123-127. doi: 10.1089/cap. 2012.0048

Takayanagi, Y., Kasahara, Y., Onaka, T., Takahashi, N., Kawada, T., and Nishimori, K. (2008). Oxytocin receptor-deficient mice developed late-onset obesity. Neuroreport 19, 951-955. 
Tamma, R., Colaianni, G., Zhu, L. L., DiBenedetto, A., Greco, G., Montemurro, G., et al. (2009). Oxytocin is an anabolic bone hormone. Proc. Natl. Acad. Sci. U.S.A. 106, 7149-7154.

Targher, G., Mantovani, A., Wang, X. B., Yan, H. D., Sun, Q. F., Pan, K. H., et al. (2020). Patients with diabetes are at higher risk for severe illness from COVID-19. Diabetes Metab. 46, 335-337.

Terrillon, S., Durroux, T., Mouillac, B., Breit, A., Ayoub, M. A., Taulan, M., et al. (2003). Oxytocin and vasopressin V1a and V2 receptors form constitutive homo- and heterodimers during biosynthesis. Mol. Endocrinol. 17, 677-691. doi: $10.1210 /$ me.2002-0222

Thienel, M., Fritsche, A., Heinrichs, M., Peter, A., Ewers, M., Lehnert, H., et al. (2016). Oxytocin's inhibitory effect on food intake is stronger in obese than normal-weight men. Int. J. Obes. 40, 1707-1714. doi: 10.1038/ijo. 2016.149

Tribollet, E., Dubois-Dauphin, M., Dreifuss, J. J., Barberis, C., and Jard, S. (1992). Oxytocin receptors in the central nervous system. Distribution, development, and species differences. Ann. N.Y. Acad. Sci. 652, 29-38.

Tsuda, T., Ueno, Y., Yoshikawa, T., Kojo, H., and Osawa, T. (2006). Microarray profiling of gene expression in human adipocytes in response to anthocyanins. Biochem. Pharmacol. 71, 1184-1197. doi: 10.1016/j.bcp.2005.12.042

Tung, Y. C., Ma, M., Piper, S., Coll, A., O’Rahilly, S., and Yeo, G. S. (2008). Novel leptin-regulated genes revealed by transcriptional profiling of the hypothalamic paraventricular nucleus. J. Neurosci. 28, 12419-12426. doi: 10. 1523/JNEUROSCI.3412-08.2008

Vaccari, C., Lolait, S. J., and Ostrowski, N. L. (1998). Comparative distribution of vasopressin $\mathrm{V} 1 \mathrm{~b}$ and oxytocin receptor messenger ribonucleic acids in brain. Endocrinology 139, 5015-5033. doi: 10.1210/endo.139.12. 6382

Vallera, C., Choi, L. O., Cha, C. M., and Hong, R. W. (2017). Uterotonic medications: oxytocin, methylergonovine, carboprost, misoprostol. Anesthesiol. Clin. 35, 207-219.

van Leeuwen, F. W., van Heerikhuize, J., van der Meulen, G., and Wolters, P. (1985). Light microscopic autoradiographic localization of $[3 \mathrm{H}]$ oxytocin binding sites in the rat brain, pituitary and mammary gland. Brain Res. 359, 320-325. doi: 10.1016/0006-8993(85)91443-x

van Zuiden, M., Frijling, J. L., Nawijn, L., Koch, S. B. J., Goslings, J. C., Luitse, J. S., et al. (2017). Intranasal oxytocin to prevent posttraumatic stress disorder symptoms: a randomized controlled trial in emergency department patients. Biol. Psychiatry 81, 1030-1040.

Vaughan, C. H., Shrestha, Y. B., and Bartness, T. J. (2011). Characterization of a novel melanocortin receptor-containing node in the SNS outflow circuitry to brown adipose tissue involved in thermogenesis. Brain Res. 1411, 17-27. doi: 10.1016/j.brainres.2011.07.003

Verbalis, J. G. (1999). The brain oxytocin receptor(s)? Front. Neuroendocrinol. 20, $146-156$.

Verbalis, J. G., Blackburn, R. E., Hoffman, G. E., and Stricker, E. M. (1995b). Establishing behavioral and physiological functions of central oxytocin: insights from studies of oxytocin and ingestive behaviors. Adv. Exp. Med. Biol. 395, 209-225.

Verbalis, J. G., Blackburn, A. N., Hoffman, G. E., and Stricker, E. M. (1995a). "Establishing behavioral and physiological functions of central oxytocin: insights from studies of oxytocin and ingestive behvaviors," in Oxytocin, eds R. Ivell and J. Russell (New York, NY: Plenum Press), 209-225.

Vila, G., Riedl, M., Resl, M., van der Lely, A. J., Hofland, L. J., Clodi, M., et al. (2009). Systemic administration of oxytocin reduces basal and lipopolysaccharideinduced ghrelin levels in healthy men. J. Endocrinol. 203, 175-179. doi: 10 . 1677/JOE-09-0227

Wald, H. S., Chandra, A., Kalluri, A., Ong, Z. Y., Hayes, M. R., and Grill, H. J. (2020). NTS and VTA oxytocin reduces food motivation and food seeking. Am. J. Physiol. Regul. Integr. Comp. Physiol. 319, R673-R683. doi: 10.1152/ajpregu. 00201.2020

Wallace Fitzsimons, S. E., Chruscicka, B., Druelle, C., Stamou, P., Nally, K., Dinan, T. G., et al. (2019). A ghrelin receptor and oxytocin receptor heterocomplex impairs oxytocin mediated signalling. Neuropharmacology 152, 90-101. doi: 10.1016/j.neuropharm.2018.12.022

Welch, M. G., Margolis, K. G., Li, Z., and Gershon, M. D. (2014). Oxytocin regulates gastrointestinal motility, inflammation, macromolecular permeability, and mucosal maintenance in mice. Am. J. Physiol. Gastrointest. Liver Physiol. 307, G848-G862. doi: 10.1152/ajpgi.00176.2014

Welch, M. G., Tamir, H., Gross, K. J., Chen, J., Anwar, M., and Gershon, M. D. (2009). Expression and developmental regulation of oxytocin (OT) and oxytocin receptors (OTR) in the enteric nervous system (ENS) and intestinal epithelium. J. Comp. Neurol. 512, 256-270.

Wilding, J. P. H., Batterham, R. L., Calanna, S., Davies, M., Gaal, L.F. Van, Lingvay, I., et al. (2021). Once-weekly semaglutide in adults with overweight or obesity. N. Engl. J. Med. 384:989.

Winter, J., Meyer, M., Berger, I., Royer, M., Bianchi, M., Kuffner, K., et al. (2021). Chronic oxytocin-driven alternative splicing of Crfr2alpha induces anxiety. Mol. Psychiatry [Epub ahead of print]. doi: 10.1038/s41380-02101141-X

Woods, S. C., Schwartz, M. W., Baskin, D. G., and Seeley, R. J. (2000). Food intake and the regulation of body weight. Annu. Rev. Psychol. 51, 255-277.

Wrobel, L., Schorscher-Petcu, A., Dupre, A., Yoshida, M., Nishimori, K., and Tribollet, E. (2011). Distribution and identity of neurons expressing the oxytocin receptor in the mouse spinal cord. Neurosci. Lett. 495, 49-54. doi: 10.1016/j.neulet.2011.03.033

Wu, C. L., Doong, M. L., and Wang, P. S. (2008). Involvement of cholecystokinin receptor in the inhibition of gastrointestinal motility by oxytocin in ovariectomized rats. Eur. J. Pharmacol. 580, 407-415. doi: 10.1016/j.ejphar. 2007.11.024

Wu, C. L., Hung, C. R., Chang, F. Y., Pau, K. Y., and Wang, P. S. (2003). Pharmacological effects of oxytocin on gastric emptying and intestinal transit of a non-nutritive liquid meal in female rats. Naunyn Schmiedebergs Arch. Pharmacol. 367, 406-413. doi: 10.1007/s00210-003-0690-y

Wu, L., Meng, J., Shen, Q., Zhang, Y., Pan, S., Chen, Z., et al. (2017). Caffeine inhibits hypothalamic A1R to excite oxytocin neuron and ameliorate dietary obesity in mice. Nat. Commun. 8:15904. doi: 10.1038/ncomms15904

Wu, Z., Xu, Y., Zhu, Y., Sutton, A. K., Zhao, R., Lowell, B. B., et al. (2012). An obligate role of oxytocin neurons in diet induced energy expenditure. PLoS One 7:e45167. doi: 10.1371/journal.pone.0045167

Xi, D., Long, C., Lai, M., Casella, A., O’Lear, L., Kublaoui, B., et al. (2017). Ablation of oxytocin neurons causes a deficit in cold stress response. J. Endocr. Soc. 1, 1041-1055. doi: 10.1210/js.2017-00136

Xiao, L., Priest, M. F., Nasenbeny, J., Lu, T., and Kozorovitskiy, Y. (2017). Biased oxytocinergic modulation of midbrain dopamine systems. Neuron 95, 368.e5384.e5. doi: 10.1016/j.neuron.2017.06.003

Yamashita, H., Okuya, S., Inenaga, K., Kasai, M., Uesugi, S., Kannan, H., et al. (1987). Oxytocin predominantly excites putative oxytocin neurons in the rat supraoptic nucleus in vitro. Brain Res. 416, 364-368. doi: 10.1016/00068993(87)90920-6

Yamashita, M., Takayanagi, Y., Yoshida, M., Nishimori, K., Kusama, M., and Onaka, T. (2013). Involvement of prolactin-releasing peptide in the activation of oxytocin neurones in response to food intake. J. Neuroendocrinol. 25, 455465. doi: 10.1111/jne.12019

Yamasue, H., Yee, J. R., Hurlemann, R., Rilling, J. K., Chen, F. S., MeyerLindenberg, A., et al. (2012). Integrative approaches utilizing oxytocin to enhance prosocial behavior: from animal and human social behavior to autistic social dysfunction. J. Neurosci. 32, 14109-14117. doi: 10.1523/JNEUROSCI. 3327-12.2012

Yang, Z., Han, D., and Coote, J. H. (2009). Cardiac sympatho-excitatory action of PVN-spinal oxytocin neurones. Auton. Neurosci. 147, 80-85. doi: 10.1016/j. autneu.2009.01.013

Yao, S., Bergan, J., Lanjuin, A., and Dulac, C. (2017). Oxytocin signaling in the medial amygdala is required for sex discrimination of social cues. eLife 6:e31373. doi: $10.7554 /$ eLife.31373

Yi, K. J., So, K. H., Hata, Y., Suzuki, Y., Kato, D., Watanabe, K., et al. (2015). The regulation of oxytocin receptor gene expression during adipogenesis. J. Neuroendocrinol. 27, 335-342.

Yoshida, M., Takayanagi, Y., Inoue, K., Kimura, T., Young, L. J., Onaka, T., et al. (2009). Evidence that oxytocin exerts anxiolytic effects via oxytocin receptor expressed in serotonergic neurons in mice. J. Neurosci. 29, 2259-2271. doi: 10.1523/JNEUROSCI.5593-08.2009

Yoshimura, R., Kiyama, H., Kimura, T., Araki, T., Maeno, H., Tanizawa, O., et al. (1993). Localization of oxytocin receptor messenger ribonucleic acid in the rat brain. Endocrinology 133, 1239-1246. 
Yosten, G. L., and Samson, W. K. (2014). Neural circuitry underlying the central hypertensive action of nesfatin-1: melanocortins, corticotropin-releasing hormone, and oxytocin. Am. J. Physiol. Regul. Integr. Comp. Physiol. 306, R722-R727. doi: 10.1152/ajpregu.00396.2013

Young, L. J., and Barrett, C. E. (2015). Can oxytocin treat autism? Science 347, $825-826$.

Young, W. S. III, Shepard, E., Amico, J., Hennighausen, L., Wagner, K. U., LaMarca, M. E., et al. (1996). Deficiency in mouse oxytocin prevents milk ejection, but not fertility or parturition. J. Neuroendocrinol. 8, 847-853.

Yuan, J., Zhang, R., Wu, R., Gu, Y., and Lu, Y. (2020). The effects of oxytocin to rectify metabolic dysfunction in obese mice are associated with increased thermogenesis. Mol. Cell Endocrinol. 514:110903. doi: 10.1016/j.mce.2020. 110903

Zhang, B., Qiu, L., Xiao, W., Ni, H., Chen, L., Wang, F., et al. (2021). Reconstruction of the hypothalamo-neurohypophysial system and functional dissection of magnocellular oxytocin neurons in the brain. Neuron 109, 331.e7-346.e7. doi: 10.1016/j.neuron.2020.10.032

Zhang, G., Bai, H., Zhang, H., Dean, C., Wu, Q., Li, J., et al. (2011). Neuropeptide exocytosis involving synaptotagmin-4 and oxytocin in hypothalamic programming of body weight and energy balance. Neuron 69, 523-535. doi: 10.1016/j.neuron.2010.12.036

Zhang, G., and Cai, D. (2011). Circadian intervention of obesity development via resting-stage feeding manipulation or oxytocin treatment. Am. J. Physiol. Endocrinol. Metab. 301, E1004-E1012.

Zhang, H., Wu, C., Chen, Q., Chen, X., Xu, Z., Wu, J., et al. (2013). Treatment of obesity and diabetes using oxytocin or analogs in patients and mouse models. PLoS One 8:e61477. doi: 10.1371/journal.pone.0061477

Zhang, Z. H., and Felder, R. B. (2004). Melanocortin receptors mediate the excitatory effects of blood-borne murine leptin on hypothalamic paraventricular neurons in rat. Am. J. Physiol. Regul. Integr. Comp. Physiol. 286, R303-R310. doi: 10.1152/ajpregu.00504.2003
Zhou, F., Yu, T., Du, R., Fan, G., Liu, Y., Liu, Z., et al. (2020). Clinical course and risk factors for mortality of adult inpatients with COVID-19 in Wuhan, China: a retrospective cohort study. Lancet 395, 1054-1062. doi: 10.1016/ S0140-6736(20)30566-3

Zigman, J. M., Jones, J. E., Lee, C. E., Saper, C. B., and Elmquist, J. K. (2006). Expression of ghrelin receptor mRNA in the rat and the mouse brain. J. Comp. Neurol. 494, 528-548.

Conflict of Interest: JB has a financial interest in OXT Therapeutics, Inc., a company developing highly specific and stable analogs of oxytocin to treat obesity and metabolic disease. The authors' interests were reviewed and are managed by their local institutions in accordance with their conflict of interest policies.

The remaining authors declare that the research was conducted in the absence of any commercial or financial relationships that could be construed as a potential conflict of interest.

Publisher's Note: All claims expressed in this article are solely those of the authors and do not necessarily represent those of their affiliated organizations, or those of the publisher, the editors and the reviewers. Any product that may be evaluated in this article, or claim that may be made by its manufacturer, is not guaranteed or endorsed by the publisher.

Copyright (C) $2021 \mathrm{Niu}$, Tong and Blevins. This is an open-access article distributed under the terms of the Creative Commons Attribution License (CC BY). The use, distribution or reproduction in other forums is permitted, provided the original author(s) and the copyright owner(s) are credited and that the original publication in this journal is cited, in accordance with accepted academic practice. No use, distribution or reproduction is permitted which does not comply with these terms. 